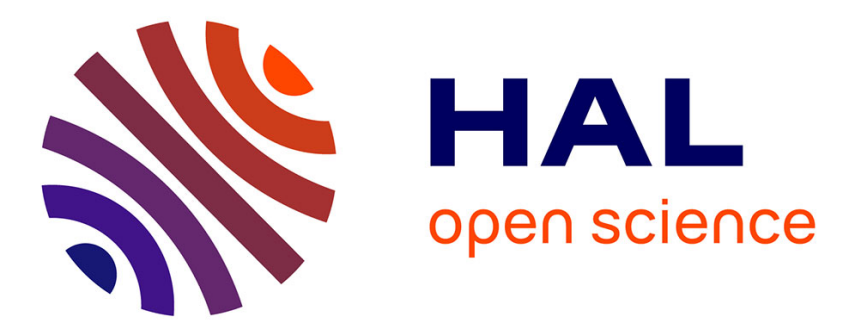

\title{
The role of energetic ion bombardment during growth of TiO2 thin films by reactive sputtering
}

\author{
A Amin, D Köhl, M Wuttig
}

\section{To cite this version:}

A Amin, D Köhl, M Wuttig. The role of energetic ion bombardment during growth of TiO2 thin films by reactive sputtering. Journal of Physics D: Applied Physics, 2010, 43 (40), pp.405303. 10.1088/0022-3727/43/40/405303 . hal-00569723

\section{HAL Id: hal-00569723 \\ https://hal.science/hal-00569723}

Submitted on 25 Feb 2011

HAL is a multi-disciplinary open access archive for the deposit and dissemination of scientific research documents, whether they are published or not. The documents may come from teaching and research institutions in France or abroad, or from public or private research centers.
L'archive ouverte pluridisciplinaire HAL, est destinée au dépôt et à la diffusion de documents scientifiques de niveau recherche, publiés ou non, émanant des établissements d'enseignement et de recherche français ou étrangers, des laboratoires publics ou privés. 


\title{
The role of energetic ion bombardment during growth of $\mathrm{TiO}_{2}$ thin films by reactive sputtering
}

\author{
A. Amin, D. Köhl, M. Wuttig ${ }^{1}$ \\ I. Institute of Physics (IA), RWTH Aachen University, D-52056 Aachen, Germany
}

\begin{abstract}
TiO}_{2}$ thin films have been deposited by several different sputtering processes: i) dc Magnetron Sputtering (dcMS) employing various geometrical conditions, ii) Ion-Assisted dc Magnetron Sputtering (IAS) where additional ion bombardment of the growing films was performed with an auxiliary ECR ion source and iii) High Power Impulse Magnetron Sputtering (HiPIMS). Films have been investigated mainly by grazing incidence X-ray diffraction and atomic force microscopy. It is shown that the highly energetic oxygen ions inherent in reactive sputtering of metal oxides are the dominant energetic species governing structure formation of $\mathrm{TiO}_{2}$ films by their kinetic impact. The trajectories of these energetic oxygen ions strongly depend on the shape of the erosion trace and hence on the age of the target, which therefore has a strong influence on structure formation. Furthermore, in a HiPIMS discharge the role of this energetic oxygen ion bombardment is strongly intensified due to the increased target voltage and the lower deposition rate compared to a dcMS discharge. It is also demonstrated that films with pure rutile structure which are stable under a post-deposition thermal treatment can be deposited under intense energetic ion bombardment at low temperatures either by HiPIMS at high peak power densities or by ionassisted dcMS.
\end{abstract}

\section{PACS 81.15.Cd, 81.15.Jj, 68.55.ag}

\section{Introduction}

Upon sputter deposition of $\mathrm{TiO}_{2}$, the resulting thin films generally exhibit two crystalline structures, anatase and rutile [1]. These phases are well distinguishable in terms of their physical properties. For example, the rutile phase is known for its comparatively high mass density $\left(4.23 \mathrm{~g} / \mathrm{cm}^{3}\right)$ [2] and, in comparison to other common metal oxides, high refractive index of up to 2.75 at $589 \mathrm{~nm}$ [2]. The anatase phase in turn is characterized by a very pronounced photocatalytic activity $[3,4]$ in combination with small water contact angles (hydrophilicity). Consequently, in a wide range of industrial applications different crystalline modifications of $\mathrm{TiO}_{2}$ are required to meet the needs of the specific application. As an example, anatase $\mathrm{TiO}_{2}$ is applied to fabricate self-cleaning [4,5] or antibacterial surfaces [4]. Optical coatings also profit from the wetting behaviour of the film which results in an anti-fogging effect [4]. Applications for the rutile structure comprise e.g. the fabrication of antireflective coatings $[6,7,8]$. It is evident that the precise control of the film structure is a key requirement to tailor the performance of the film for the targeted application. Therefore, structure control presently constitutes one of the main challenges in the design of adequate coating processes. A variety of deposition techniques such as sol-gel processes [9], chemical vapour deposition [10], evaporation [11], sputter deposition [16,19] and ion beam assisted deposition [12,13] have already been employed to deposit $\mathrm{TiO}_{2}$ thin films. Among these techniques sputter deposition is favoured by the large area coating industry because of the excellent scalability of the process. Especially during the last decade significant endeavours have been made to understand the structure formation of sputtered $\mathrm{TiO}_{2}$ thin films. These efforts were mainly driven by the interest to apply such films as photocatalysts. Special emphasis has been put on understanding the correlation between process parameters and the formation of the anatase and rutile crystalline phases in thin films. Consequently, a large number of studies have been published that investigate structure formation as a function of various deposition parameters such as e.g. total pressure, oxygen partial pressure, substrate temperature, deposition rate, film thickness, magnetron configuration and

1 Corresponding author: E-mail: wuttig@physik.rwth-aachen.de, Phone: +49 (0) 24180 27155, Fax: +49

(0) 2418022331 
electrical discharge properties including the ion bombardment of the substrate. Furthermore, different magnetron sputtering types such as dcMS [14-18], RFMS [18-25], pulsed unipolar \& bipolar MS [26-33] and HiPIMS [34-37] have been utilized. Regarding the influence of deposition parameters on structure formation there is a consensus throughout most publications that energetic particle bombardment is one of the most important parameters governing phase formation. However, there does not seem to be a consensus about the bombarding species, their required energies and finally about the exact mechanism by which phase formation is triggered as a function of bombardment. Moreover, most studies even ignore the role of highly energetic negatively charged oxygen ions. Although the marked influence of negative oxygen ion bombardment inherent in the sputter discharge has been shown already for a variety of materials [cf e.g. 38-43], it is often disregarded in the structure formation of sputtered $\mathrm{TiO}_{2}$ films. Instead, many authors conclude that low energy ion bombardment due to positive ions accelerated by the differences in plasma and substrate potentials is the main contributor to phase formation. On the other hand, several investigations of deposition processes different from sputtering exist that clearly show the importance of the high energy ion bombardment on $\mathrm{TiO}_{2}$ structure formation. Amongst these studies are investigations of oxygen ion assisted evaporation of $\mathrm{TiO}_{2}$ [44], ion beam dynamic mixing [45] and reactive ion cluster beam evaporation [46,47] which have in common a strong energetic ion bombardment of the growing films. In contrast, other techniques such as electron beam [18,48] and vacuum arc plasma evaporation [49] typically lack strong energetic particle bombardment. Hence, comparing the resulting film structure if methods of deposition are chosen where the energetic bombardment is either pronounced or very low enables the conclusion that, if the films are crystalline, anatase films are grown without intense ion bombardment, while strong ion bombardment promotes the growth of the rutile phase. However, only very few studies exist on sputtering of $\mathrm{TiO}_{2}$ that discuss the existence of highly energetic oxygen ions created at the sputter target surface and their possible influence on film properties [e.g. 18,25,34]. Therefore, it is our main goal to demonstrate

i) the influence of energetic ion bombardment (i.e. with energies significantly larger than typical plasma potentials) and to show that it is responsible for the effects that are often attributed to low energy bombardment,

ii) that there are distinct fingerprints in the properties of reactively sputtered $\mathrm{TiO}_{2}$ films which provide both an unambiguous proof for the existence of highly energetic negative ions and clarify the influence of these particles on film properties and

iii) that the action of these negative oxygen ions can be controlled to yield desired film properties by means of e.g. ion-assisted reactive dc magnetron sputtering, tailoring of target or chamber geometry and High Power Impulse Magnetron Sputtering (HiPIMS).

To achieve this goal, we first investigate the properties of $\mathrm{TiO}_{2}$ films fabricated in the IAS process under additional tailored ion bombardment. From these experiments we deduce the typical fingerprints of the influence of energetic ion bombardment on structure formation. This allows for identifying the possible action of energetic particle bombardment in the dcMS and HiPIMS processes. Unambiguous proof that $\mathrm{O}^{-}$is the dominant bombarding species in these processes is possible since the existence of these ions in reactive sputter processes has been confirmed and their impact on the structure formation in reactive sputter processes has been investigated for a variety of materials. It was first proven by Tominaga and co-workers by utilizing time-of-flight measurements during sputtering of $\mathrm{ZnO}$ that oxygen ions with energies equivalent to approximately the full cathode potential [50] strongly influence structure formation [51]. These ions are created at the target surface from collisions with the sputtering species. A possible formation mechanism is discussed in [52] and implies a correlation between the emission yield of negative oxygen ions and secondary electrons. This correlation has been shown in a comprehensive investigation of oxygen ion energies and emission intensities for a large variety of sputtered metal oxides by utilizing energy-resolved mass spectrometry [53]. The existence of highly energetic negative oxygen ions for sputtering group IV transition metal oxides has been demonstrated for $\mathrm{Ti}$ [54], $\mathrm{Zr}$ and $\mathrm{Hf}$ [40] where in the latter case it has also been shown that the emission intensity is strong compared e.g. to group V transition metal oxides. The strong influence of energetic oxygen ion bombardment on structure formation has been demonstrated e.g. for $\mathrm{ZrO}_{2}$ $[39,55]$. Interpreting the results summarized in [53] there seems to be a trend that oxygen ion emission is largest for alkali and alkaline earth metal oxides and decreases with increasing valence for the transition metal oxides. Since $\mathrm{Zn}$ has a low valence of 2 this trend is also consistent with the fact that sputtered $\mathrm{ZnO}$ films show strong damage due to energetic oxygen ion bombardment. For this material it was also demonstrated that the trajectories of the negative oxygen ions are strongly governed by the geometry of the 
racetrack and therefore by the age of the target [38]. This is a consequence of the creation of these ions directly at the target surface and the subsequent acceleration in the very narrow cathode sheath where the electric potential gradient is almost perpendicular to the target surface even at the racetrack. Consequently, this correlation between negative ion trajectories and the target profile is universally valid and not restricted to $\mathrm{ZnO}$. For this reason, any dependence of $\mathrm{TiO}_{2}$ film properties on the age of the target provides strong evidence for an influence of energetic negative ion bombardment originating from the target surface.

\section{Experimental procedure}

$\mathrm{TiO}_{2}$ films have been deposited by ion-assisted dc Magnetron Sputtering (IAS), conventional dc Magnetron Sputtering (dcMS) under different geometrical conditions and by High Power Impulse Magnetron Sputtering (HiPIMS). Therefore, films have been fabricated in two different sputter deposition tools. One of the systems is equipped with an auxiliary ECR ion source and enables simultaneous bombardment of the growing film with ions during reactive sputter deposition. The details of the system have been described elsewhere [56,57]. A metallic target of $76 \mathrm{~mm}$ in diameter was sputtered in a mixed $\mathrm{Ar} / \mathrm{O}_{2}$ atmosphere. Low total pressures of 0.3 to $0.4 \mathrm{~Pa}$ have been employed for film deposition to ensure appropriate conditions for operation of the ion gun and a large mean free path for the ions produced. Discharge currents of 1.2 to 1.6 Amperes were used to compensate for the slightly increased target to substrate distance of $80 \mathrm{~mm}$ necessary for the simultaneous bombardment. Investigations on the influence of racetrack and deposition geometry for dcMS and the HiPIMS depositions were carried out in a second deposition system at typical working pressures of $0.8 \mathrm{~Pa}$ at discharge currents of 0.9 to 1.2 Amperes and a target to substrate distance of $55 \mathrm{~mm}$. An Advanced Energy Pinnacle dc power supply $(2 \times 10 \mathrm{~kW})$ was used for all depositions. One channel of the supply is combined with a Melec SPIK 2000A pulser for the HiPIMS process. Both deposition tools are equipped with identical magnetron cathodes to ensure comparability. Microscope glass slides were used as substrates. The substrate temperature during deposition has not been measured for the specimens discussed. However, the temperature of the shield between the cathode and the substrate stage was measured for the standard $\mathrm{TiO}_{2}$ discharge conditions discussed above $(900 \mathrm{~mA}, 0.8 \mathrm{~Pa}, 55 \mathrm{~mm})$ and was found to saturate at around $170{ }^{\circ} \mathrm{C}$ after about 3 hours in oxide mode. It is therefore expected that the substrate temperature is lower or equal to this temperature depending on the deposition time. Oxygen partial pressures during deposition were not recorded. However, after an upgrade of one of the deposition systems it was determined that in a dcMS process at standard conditions $(900 \mathrm{~mA}, 0.8 \mathrm{~Pa})$ the partial pressure varies from approximately 70 to $190 \mathrm{mPa}$ if the oxygen flow is varied from low, i.e. close to the transition but in the oxide mode, to high flows. The structural properties of the films were investigated by X-ray diffraction in grazing incidence geometry (GI-XRD) at an angle of $0.7^{\circ}$ utilizing a Philips X'Pert Pro MRD (45 kV, 40 $\mathrm{mA}$ ) using $\mathrm{CuK}_{\alpha}$ radiation. The surface topography was investigated employing a DI Dimension 3100 Nanoscope atomic force microscope. All images shown in this work have been post-processed with a $5 \times 5$ convolution matrix to enhance surface corrugation. The thickness of the investigated films was derived from simulations of both X-ray reflectometry spectra and optical measurements. Therefore ellipsometry spectra were recorded in the range of 0.73 to $5.13 \mathrm{eV}$ with a Woollam M-2000UI variable angle spectroscopic ellipsometer. Reflectance and transmittance spectra were measured in the range of 1.13 to $6.53 \mathrm{eV}$ using a Perkin Elmer Lambda 25 UV-VIS spectrometer. The optical spectra have been modelled using a parametric description (OJL model) of the dielectric function [58], employing the Scout software [59].

\section{Results}

\subsection{Ion-assisted reactive dc magnetron sputtering}

Ion bombardment can influence film growth by a variety of different mechanisms. Preferential damage of specifically oriented grains for example would strongly depend on the angle of incidence and the texture of the film. The energy and inertia of the bombarding species should generally determine the balance between implantation, densification and sputtering effects. Even chemical reactions can occur if a reactive ion species is used such as in the case of oxygen ion bombardment of $\mathrm{TiO}_{2}$ films.

Since the deposition tool utilized does not allow for a change of the angle of incidence of the ions, the impact of preferential damage has not been investigated systematically. However, typical sputter deposited $\mathrm{TiO}_{2}$ films do not exhibit pronounced crystallographic texture. Hence, any effect that is based on the interaction between the ion beam and specifically oriented grains is not expected to depend on the angle of incidence. To identify a possible influence of chemical interaction we have used both oxygen ions and inert xenon ions in our experiments. 
To investigate the influence of ion bombardment on film growth, deposition conditions were used that typically promote the formation of mixed anatase and rutile film structures in the as-deposited state. Additional ion bombardment was then applied and the change of film structure investigated. Two reference samples produced without auxiliary bombardment were usually deposited at the beginning and at the end of each bombardment series, respectively, to confirm process stability. Figure 1 shows grazing incidence XRD spectra of films grown with additional $\mathrm{O}^{+}$ion bombardment. For the bombarded films the ion energy was increased from 150 to $300 \mathrm{eV}$ while the power of the microwave source of the ion gun was kept fixed. As a consequence, the current density of the ion beam also increased with ion energy from approximately $0.7 \mu \mathrm{A} /$ $\mathrm{cm}^{2}$ to about $2.3 \mu \mathrm{A} / \mathrm{cm}^{2}$, as measured with a flat probe at the substrate position prior to deposition. These current densities correspond to relative arrival ratios of ions to $\mathrm{TiO}_{2}$ molecules of about $1.1 \%\left(0.7 \mu \mathrm{A} / \mathrm{cm}^{2}\right)$ to $3.7 \%\left(2.3 \mu \mathrm{A} / \mathrm{cm}^{2}\right)$ as derived from the deposition rate of the films. It is evident that even at low arrival ratios and for ion energies that are small compared to the typical energies of negatively charged oxygen ions generated at the target surface $(\sim 400-500 \mathrm{~V})$ there is a significant influence on the film structure upon the bombardment. Particularly striking is the selective deterioration of the anatase phase. While the rutile phase is almost unaffected by the additional ion bombardment, the anatase phase completely disappears from the spectra at high current densities and ion energies. This difference might be due to the higher density of the rutile phase, which leads to an increased stability against ion erosion.

The impact of oxygen ion bombardment also clearly manifests itself in changes of surface topography as shown for two films in figure 2. The un-bombarded reference film exhibits surface features with two different lateral length scales. To some extent it seems that the surface can be described by regularly arranged small-grained features constituting a background on which an open structure of rather irregular features with significantly larger mean widths has grown. Upon ion bombardment the large features completely vanish and the surface consists of the small-grained features alone. To simplify the discussion of AFM images we will henceforth refer to the regular small-grained surface structure, such as observed for sample IO-5C, as a type 1 surface while a type 2 surface denotes the irregular structural features observed for sample IO-1C. A very similar dependence of surface topography on phase composition of $\mathrm{TiO}_{2}$ films has already frequently been reported in the literature [e.g. 15,16,20,22,23,25,30], where it is typically found that a type 1 surface is related to growth conditions that yield rutile films while anatase structures seem to exhibit a type 2 surface. It should be mentioned here that our investigations also revealed a correlation between surface topography and film thickness. However, the crystal structure similarly depends on film thickness (see for example [16,31]) and hence the changes of the observed surface topography coincide with the change of the crystal structure (rutile or anatase) present at the film surface.

In [15] it was found for reactive ion beam mixing of $\mathrm{TiO}_{2}$ that the crystal quality strongly depends on the ion species. To investigate possible differences between reactive and inert species in ion-assisted sputtering we have performed experiments also with an inert ion species. Therefore, xenon was used as the bombarding species. While the ion energy was kept fixed at $180 \mathrm{eV}$, the current density was increased from approximately 0.6 to $1.2 \mu \mathrm{A} / \mathrm{cm}^{2}$, which corresponds to arrival ratios of $0.9 \%$ and $1.8 \%$. Figure 3 shows grazing incidence XRD spectra from which it is evident that again a striking change in film structure occurs upon increasing the intensity of the ion bombardment. It is especially noteworthy that at low current densities of $0.6 \mu \mathrm{A} / \mathrm{cm}^{2}$ formation of the rutile phase is noticeably promoted while the anatase phase generally deteriorates upon additional ion bombardment. The surface topography (fig. 4) also shows changes very similar to those found for the oxygen bombardment. A clear trend from a type 2 surface with very small type 1 contribution without ion bombardment towards a pronounced type 1 surface with increasing intensity of the ion bombardment is evident.

From comparison of the results from oxygen and xenon ion bombardment we can conclude that the nature of the bombarding species (reactive or inert) does not play a major role in determining the film structure upon ion bombardment.

To summarize the results from experiments with controlled additional ion bombardment it can be stated that ion bombardment selectively hinders the formation of the anatase phase. At low intensity it was also found that growth of the rutile phase can be promoted by adequate ion bombardment. Furthermore, besides the XRD spectra, the resulting surface topography also clearly indicates the change in structure and hence the consequences of ion bombardment. These results are now applied to discuss the influence of the racetrack geometry of a reactively sputtered Ti-target (dcMS) on structure formation, since the racetrack of the target itself constitutes a source of highly energetic ions in reactive sputtering. Films will also be shown that have been deposited under conditions where this oxygen ion bombardment from the target surface has been 
reduced by geometrical means. Finally, structure formation of $\mathrm{TiO}_{2}$ will be discussed for reactive HiPIMS discharges where a significantly stronger influence of ion bombardment is expected compared to dcMS.

\subsection{Influence of racetrack geometry in a static dcMS process}

As discussed in the introduction, during reactive deposition of $\mathrm{TiO}_{2}$ negatively charged oxygen ions are created at the oxidized fraction of the target surface due to collisions with the sputtering species. These oxygen ions are accelerated and typically hit the growing film with a kinetic energy approximately equivalent to the full cathode voltage $[40,41,54]$. Since the trajectories of the negatively charged oxygen ions strongly depend on the shape of the target surface, the distribution of oxygen ion bombardment along the substrate depends on the geometry of the deposition system but also on the age of the target. Therefore, the films fabricated in our lab coaters are typically inhomogeneous in terms of the lateral distribution of oxygen ion bombardment and pronounced changes are observed upon aging of the target [38]. As sketched in figure 5 , new targets without any pronounced erosion trace produce oxygen ion bombardment predominantly towards the edge of the substrate while the use of aged targets results in focusing the ion bombardment onto the centre. Films were deposited utilizing a new and an old Ti target respectively and film properties were investigated at the centre and the edge of the substrates respectively. Regarding the influence of film thickness on crystal structure [cf e.g. 16] films have been deposited with different thicknesses for these investigations.

Figure 6 shows the XRD spectra recorded for films that have been deposited from a new target. AFM images for one of these films are presented in figure 7. There are a number of pronounced differences between film properties at the sample centre and at the edge. Starting with the crystal structure it is apparent that for all investigated films the rutile structure is more distinct at substrate positions above the racetrack of the target, even though films are thinner by about $10-15 \%$ at this position. Since a new target has been used, the area above the racetrack is subject to the most intense bombardment by negatively charged oxygen ions from the cathode as compared to other areas on the substrate. Qualitatively, this result is very similar to the structure formation under additional xenon ion bombardment at medium intensity (fig. 3). Hence, it seems that the formation of the rutile phase benefits from the bombardment. Regarding the anatase phase there is a small increase in intensity (except for the thinnest film) of the (101) peak at positions above the racetrack accompanied by an increase in peak width. In conclusion, since the integral intensities of both the anatase (101) peak and the rutile (110) peak increase above the racetrack, the films apparently exhibit better crystallization in this area. Additionally, in the same area the formation of the rutile phase seems to be favoured with respect to the anatase phase. From the peak positions (literature values marked by vertical lines) it is evident that the crystal lattice is significantly strained in the bombarded regions (above the racetrack) of the substrate. The AFM images show that at the centre of the film there is a closed type 2 surface structure. At the edge, where negative oxygen ion bombardment is most intense, a type 1 surface topography can be clearly seen which is only partially covered by an open type 2 structure.

Investigating $\mathrm{TiO}_{2}$ films sputtered from an aged target confirms our assumption that negative oxygen ion bombardment is the main reason for the structural inhomogeneities. Figures 8 and 9 clearly show that the pattern of typical fingerprints of oxygen ion bombardment has changed, which is in-line with the expected change in distribution of the ion bombardment due to altered target geometry (cf fig. 5). Now the sample centre shows an increased intensity of the rutile phase in combination with a larger width of the anatase (101) peak. Film strain also is more pronounced at the sample centre in contrast to the films from the new target as shown in figure 10 where the peak positions of the anatase peak are shown. We have used the Scherrer equation [60] to estimate the anatase grain size at the different substrate positions for the new and the old target respectively. Figure 11 shows that the grain size is significantly affected by the oxygen ion bombardment. At positions with low bombardment the grain size is increased by a factor of approximately 2 with respect to positions that are hit predominantly by the energetic ions.

In summary, these results provide unambiguous proof that highly energetic negatively charged oxygen ions created at the target surface and accelerated towards the growing film by the full cathode voltage strongly effect phase composition, strain (and thus film stress) as well as overall crystallization of reactively sputtered $\mathrm{TiO}_{2}$ films.

\subsection{Film growth by dcMS under reduced oxygen ion bombardment}

To determine what would be the resulting film structure if oxygen ion bombardment was significantly reduced, an experiment was designed where the substrates were placed in vertical direction, such that the current density of energetic oxygen ions from the target surface was lower and ion impact proceeded at 
grazing incidence. Corresponding XRD spectra are presented in figure 12, where the deposition geometry is also sketched as an inset. Sample S1 should be regarded as a reference sample here, since it was placed at the top of the "cavity" constructed by three substrates on a single carrier position. Because an aged target was utilized, sample S1 was therefore subject to oxygen ion bombardment from the target. There is no anatase peak in the diffraction pattern, but potentially a very weak rutile signal at $2 \theta \approx 27.5^{\circ}$. Sample $S 2$ is one of the samples that were placed at the sides of the carrier. Because the film thickness of this sample is quite inhomogeneous, the sample was analyzed at its thickest position, which corresponds to a film thickness very comparable to that of sample S1. Sample S2 shows a pronounced anatase (101) peak. Sample S3 was deposited in an open cavity, i.e. without a top sample. Apparently the anatase signal from this sample is even stronger. We attribute the difference between samples S2 and S3 to recoil ions that are reflected at substrate $\mathrm{S} 1$ and probably increased ion bombardment of sample S2 in comparison to sample S3. The average grain size of sample S3 has been estimated to $22 \mathrm{~nm}$ (Scherrer).

To discuss the results from this experiment it should first be noted that all samples (S1-S3) produced are very thin (compare e.g. with the thicknesses of samples shown in figures 4 and 5). With regard to the pronounced influence of film thickness on crystal quality [16], which is also evident from figures $6 \& 8$, the very weak crystalline quality of sample S1 is typical for this film thickness. Therefore it is even more striking that both samples S2 and S3 exhibit a distinctly improved anatase structure without any rutile phase. Thus reducing the intensity of the energetic oxygen ion bombardment from the sputter target enables the fabrication of films with pure anatase structure.

\subsection{Structure evolution in a HiPIMS process}

To characterize the structure formation of $\mathrm{TiO}_{2}$ films in a HiPIMS process, films have been deposited at a constant average discharge current and by applying unipolar pulses with a length of $50 \mu \mathrm{s}$. In this mode, the peak discharge current during a single pulse can be varied by changing the repetition frequency of the discharge, i.e. the length of the off-time between adjacent sputter pulses. With increasing off-time, the repetition frequency decreases and therefore the energy delivered to the sputter target during a single pulse has to increase to maintain a constant average discharge current. Hence, target voltage and, as a consequence, also the peak current increases. This behaviour is depicted in figure 13, where the discharge voltage and peak current are plotted versus off-time. The data at zero off-time correspond to the properties of a DC discharge operated at the same average target current with the pulser operated in DC mode.

Features of the HiPIMS discharge are an extremely high peak power density and a significantly increased target voltage compared to a dcMS discharge at the same average discharge current or power [61]. Consequently, the negatively charged oxygen ions that are created at the target surface and subsequently accelerated towards the growing film have much higher kinetic energies upon impact. Based on our previous investigations we therefore expect a significant increase in the influence of this ion bombardment. Additionally, there is a second effect that is expected to further increase the relative strength of the oxygen ion bombardment, which will be explained in the following. With increasing peak current density of the HiPIMS discharge, self-sputtering of the target becomes increasingly dominant since some of the sputtered species are ionized in the dense plasma and subsequently retracted towards the target surface. This significantly lowers the process efficiency, i.e. the ratio between the deposition rate and the sputtering power $[62,63]$. This reduction of the deposition rate is evident from figure 13. Since the rate of generation of the negatively charged oxygen ions is not expected to be influenced to the same extent by the increasing action of self-sputtering, this would imply an increased ratio of bombarding oxygen ions to deposited $\mathrm{TiO}_{2}$ molecules at the substrate. Consequently, in a HiPIMS discharge the concurrent increase of the energy of the bombarding ions and the increase of the relative ion flux is expected to have a significant impact on structure formation.

A series of films was sputtered at an average target current of 0.9 A. The peak power was adjusted by increasing the off-time from 800 to $2000 \mu \mathrm{s}$ for the different samples. Accordingly, the frequency of the discharge decreased from approximately 1180 to $490 \mathrm{~Hz}$ while the peak power increased from about 32 to $114 \mathrm{~kW}$. Figure 14 shows XRD spectra of the films fabricated. One of the spectra shows a sample (D1) sputtered in a dcMS process under otherwise identical conditions, which serves as a reference. XRD spectra were recorded at the sample centre and at the edge to also show the lateral in-homogeneities according to the directional oxygen ion bombardment from the target. From the reference it is evident that the utilized target exhibited only a shallow racetrack. This is evident e.g. from the intense rutile (110) peak at the substrate position opposite to the targets racetrack. From our previous investigations we know that this is an 
unambiguous fingerprint of intense oxygen ion bombardment from the cathode. Hence, for the HiPIMS films there are several clear trends:

i) At low peak currents of 50 Amperes (sample H1) the peak and integral intensities both of the anatase (101) and the rutile (110) peak are larger by a factor of 2 at the sample centre compared to the reference sample D1. There might be several reasons for that. First, a similar observation has been made when investigating the profiles of films sputtered from old or new targets, respectively (figures $6 \& 8$ ). There, an increase of the overall crystallinity of the films has been observed at substrate positions that were subject to an increased oxygen ion bombardment. Therefore, also for the HiPIMS samples energetic oxygen ion bombardment of moderate intensity (compared to samples sputtered at high peak powers) should yield an increase of crystalline phase. Even though a new target was utilized it is assumed that ion bombardment also extends to the substrate centre for reasons discussed below (issue iv). Second, since the average discharge power is increased by $33-46 \%$ for samples $\mathrm{H} 1$ - H5 compared to sample D1 due to the increase in discharge voltage, an increased transfer of thermal energy from the target and the plasma to the growing film occurs which could have a significant influence.

ii) Compared to the relative intensity of the anatase and rutile peaks of the reference D1, even at the lowest peak power (sample H1) there is already a more pronounced decrease in the anatase peak intensity at the edge of the sample where oxygen ion bombardment from the new target is strongest as compared to the centre. Also, the improvement in the rutile (110) peak intensity at the edge of the sample (above the racetrack) is not as pronounced as for sample D1. We therefore conclude that the ion bombardment in the HiPIMS discharge is significantly stronger than in the DC discharge already at medium peak currents.

iii) With increasing peak power the selective deterioration of the anatase phase becomes more pronounced especially at the sample centre. Since the discharge voltage does not significantly increase upon increasing the peak current from 50 Amperes (sample H1) to 160 Amperes (sample H5) and based on our results from ion-assisted dcMS we can understand this trend as an increase of the relative arrival ratio of oxygen ions to $\mathrm{TiO}_{2}$ molecules.

iv) With high peak powers the film structure tends to become almost homogeneous across the substrate and is very likely governed by massive energetic bombardment across the full width of the sample (H5). This fact can probably be attributed to the extension of the erosion area presumably due to a loss of magnetic confinement above the sputtered target at extreme power densities [64]. The lateral homogeneity of the ion bombardment at high peak powers (sample H5 and partially H4) is further supported by the fact that for peak currents larger than 104 Amperes the relative intensity of the rutile peaks at the centre and the edge of the samples has changed to an order that can be explained solely by the difference in film thickness between the different sample positions.

A statement should be given here about a possible influence of the film thickness on the results discussed above. Since film thickness decreases by about a factor of 2 upon increasing the peak discharge current from 50 to 160 Amperes, the thickness dependence has an influence on film structure as well. However, it has been confirmed that this effect does not alter the qualitative result by subsequent deposition of a sample with a thickness of approximately $300 \mathrm{~nm}$ at 50 Amperes peak. This sample showed a clear indication of the presence of the anatase phase (although the peak intensity is weaker than for sample H1) in contrast to sample H5 which is of similar thickness.

The change to homogeneous films with increasing power density is also reflected in the surface topography (not shown here). The samples sputtered at 50, 78 and 160 Amperes peak were mapped by AFM. The sample sputtered at 50 Amperes peak (H1) shows a mixed type 1 and 2 surface with extremely large connected regions of type 2 at the centre while towards the position above the racetrack a type 1 surface topography dominates. A similar observation was made for the sample sputtered at 78 Amperes peak $(\mathrm{H} 2)$. However, there is a shift towards a predominant type 1 surface structure in direct comparison with sample H1. At highest power densities, type 2 surface features are completely absent (H5). The film sputtered at 160 Amperes peak is solely governed by type 1 surface features at all substrate positions. These observations are fully consistent with the correlations between ion bombardment, crystal structure and surface topography discussed for the IAS and dcMS processes in the previous sections and with the XRD profile shown in figure 14. 


\subsection{Thermal stability of $\mathrm{TiO}_{2}$ grown under intense ion bombardment}

To further investigate structure formation upon energetic ion bombardment, $\mathrm{TiO}_{2}$ films have also been treated in a post-deposition thermal annealing process. Five different samples have been selected: 1) A sample (T1) grown at low oxygen partial pressure by dcMS which exhibited a very weak mixed anatase/rutile structure after deposition. 2) A sample with a pronounced mixed crystal structure deposited by dcMS at an intermediate oxygen partial pressure (T2). 3) A sample exhibiting a pronounced anatase phase and a weak rutile contribution upon dc sputtering at a high partial pressure (T3). 4) A rutile HiPIMS sample deposited at a large peak current (T4). 5) A rutile sample produced by ion-assisted reactive sputtering (T5). It has been widely accepted in the literature that recrystallization upon post-deposition thermal annealing strongly depends on the microstructure of the sample [18,33]. Typically films that are amorphous or mixed anatase/rutile exhibit pronounced anatase growth upon thermal annealing if the annealing temperature is well below the transition temperature of approximately $800{ }^{\circ} \mathrm{C}$ above which anatase $\mathrm{TiO}_{2}$ is converted into a rutile structure. Only films with a pronounced anatase structure (as-deposited) are stable under postdeposition annealing below this temperature. Therefore, it is difficult to fabricate thermally stable rutile films by sputtering at moderate temperatures since at low temperatures rutile films can be deposited which are not thermally stable while at slightly higher substrate temperatures films typically grow with a preferred anatase structure.

The samples investigated have been annealed for 2 hours in air at a temperature of $270{ }^{\circ} \mathrm{C}$. Some of the specimens have been further treated by an additional annealing process at $400{ }^{\circ} \mathrm{C}$ in vacuum for 2 hours. The results of these experiments are shown in figure 15. It is evident that samples $\mathrm{T} 1$ - T3 exhibit exactly the behaviour described above, i.e. it is not possible to fabricate a thermally stable rutile film by standard dcMS. However, it is evident from the structure of samples T4 and T5 that sufficient high energy ion bombardment during deposition either by ion-assisted dcMS or HiPIMS yields rutile films that are comparatively stable. We propose that this behaviour is a consequence of the microstructure of the as-deposited films. We assume that films grown under low ion bombardment and without a pronounced anatase phase contain a significant contribution of an amorphous phase which crystallizes into the anatase phase at temperature well below 800 ${ }^{\circ} \mathrm{C}$ for energetic reasons explained in [18]. Films grown under intense high energy ion bombardment on the contrary are assumed to have fully crystallized into the rutile phase during deposition and hence formation of an anatase phase is energetically not possible.

\section{Discussion}

The results from ion-assisted reactive sputtering and from the investigation of lateral sample profiles for a standard dcMS process utilizing new and aged targets, respectively, provide unambiguous proof that highly energetic ion bombardment (especially negative oxygen ions generated at the target surface) needs to be regarded probably as one of the most important quantities governing structure formation during reactive sputter deposition of $\mathrm{TiO}_{2}$ films.

It has been found that the rutile phase of $\mathrm{TiO}_{2}$ selectively grows with increasing energy/intensity of the bombardment. For the films sputtered by standard dcMS (figures $6 \& 8$ ) it has been found that the crystallization into the rutile phase is promoted by the high energy oxygen ion bombardment inherent in the deposition technique. For films grown by ion-assisted sputtering an increase in the intensity of the rutile (110) peak has been found only at low ion current densities (sample IX-2C in figure 3) while higher current densities and energies already lead to a slight deterioration also of the rutile phase. For films deposited onto vertically aligned substrates (with respect to the target surface) films have been deposited without detectable traces of the rutile phase (samples S2 \& S3 in figure 12). In conclusion, energetic bombardment is mandatory for the nucleation of the rutile phase. This can be explained by the fact that rutile is the high-energy phase of $\mathrm{TiO}_{2}$ and, in contrast to the anatase phase, therefore requires a sufficient amount of energy to nucleate [cf e.g. $18,23,28,29]$.

According to our investigations the anatase phase typically deteriorates upon increase of high energy ion bombardment. This is likely a direct consequence of the fact that rutile nucleation is strongly promoted under such conditions. However, for several samples a selective deterioration of the anatase (101) peak has also been observed without a simultaneous increase of the rutile (110) peak intensity (compare e.g. samples IO1C and IO-3C in figure 1). Therefore energetic ion bombardment might have an additional destructive influence on the crystallization or the growth of the anatase phase aside the promotion of rutile nucleation and growth. As yet, there is no clear proof for this assumption. Under conditions that result in relatively weak bombardment of the growing film (vertical substrates, figure 12) the growth of the anatase phase is strongly promoted. This behaviour has frequently been observed in the literature and has been attributed to 
the fact that the amorphous phase has a density very similar to the density of anatase $\mathrm{TiO}_{2}$ but significantly lower than the density of the rutile structure. Therefore, crystallization into the anatase phase is energetically favoured at medium temperatures and energies which do not yet promote nucleation of the rutile phase [18]. Anatase growth also profits from the fact that anatase grains seem to grow much faster than rutile grains under such conditions [18].

In many cases (see figures $6 \& 8$ for example) the bombardment by high energy oxygen ions does not only promote the growth of the rutile phase but also seems to improve the overall crystallinity of the films which is evident from the increase of the integral intensity of both the anatase (101) and the rutile (110) peak. An increase of the quality of anatase films for medium ion bombardment has also been found in literature [44]. We attribute this to an increased nucleation density of the anatase phase, in particular.

Structure formation in a HiPIMS discharge is very similar to the ion-assisted sputtering process on the one hand and to the observations made upon investigating the influence of the target racetrack on the other hand. There is a very clear correlation of the structure with the trajectories of energetic negative oxygen ions. The structural changes are much more pronounced than in a DC process, which lead to the assumption of an increased bombardment intensity. Hence we think that this is a strong proof for the fact that also in a HiPIMS discharge negative oxygen ions with high energies are the dominant ion species that governs structure formation. We therefore propose that positively charged ions, in the absence of a large substrate bias potential, obtain comparatively low energies that have a much weaker influence on the crystallization of $\mathrm{TiO}_{2}$.

In consequence, the existence and where applicable the trajectories of the negatively charged oxygen ions emanating from the target surface need to be regarded as an important parameter in the discussion of the structural evolution of $\mathrm{TiO}_{2}$ films.

In summary our experimental findings clearly show possibilities and limitations to tailor $\mathrm{TiO}_{2}$ films for applications where the phase composition is an important parameter. We have demonstrated that a HiPIMS discharge apparently does not meet the prerequisites for fabricating films with anatase phase featuring large grain sizes. On the other hand, the growth of thermally stable films with pure rutile structure is highly promoted in a HiPIMS process.

We also showed that ion bombardment has a strong influence on surface topography. The observed surface features can be clearly distinguished. For a variety of films sputtered under different environmental conditions (oxygen partial pressure, temperature, etc.) and with different film thicknesses we generally observe (not shown here) that rutile films exhibit a type 1 surface structure while the onset of anatase phase formation is typically accompanied by partial coverage of that surface by type 2 features. Strongly anatase films finally do not exhibit type 1 features at all. Hence, the explicit reduction of type 2 surface features in favour of the remaining type 1 surface upon ion bombardment is also a clear indication of the promotion of the rutile structure and the accompanying deterioration of the anatase phase. Due to this inter-correlation between crystal structure and surface topography of as-deposited films, ion bombardment typically affects both crystallinity and topography.

\section{Conclusion}

There is clear evidence that, besides directly accessible deposition conditions, ion bombardment plays a dominant role in structure formation. There is also unambiguous proof that it is the bombardment of the growing films by highly energetic negative oxygen ions inherent in the sputtering process that mainly governs structure formation rather than bombardment by low energy positive ions from the plasma. Energetic bombardment strongly promotes the growth of the rutile films while anatase films typically profit from growth conditions that are characterized by the absence of (or very weak) ion bombardment. Purely rutile films can be grown under intense ion bombardment. In contrast to weakly anatase mixed films grown under low energy ion bombardment, such films are thermally very stable since complete crystallization into the rutile phase is promoted by the intense bombardment during deposition and hence conversion into an anatase phase is energetically unfavourable. This knowledge further contributes to a comprehensive understanding of the correlation between film structure and process parameters and therefore constitutes another important step towards tailoring the structure and morphology of $\mathrm{TiO}_{2}$ films.

\section{Acknowledgements}

Financial support by the Deutsche Forschungsgemeinschaft (Wu 243/18-1) is gratefully acknowledged.

\section{References}


[1] Wiggins M D, Nelson M C and Aita C R 1996 J. Vac. Sci. Technol. A 14772

[2] CRC Handbook of Chemistry and Physics, $78^{\text {th }}$ edn., CRC Press, Boca Raton, NY, p. 4-132, 137

[3] Fujishima A, Rao T N and Tryk D A 2000 Journal of Photochemistry and Photobiology C: Photochemistry Reviews 1 1-21

[4] Fujishima A, Zhang, X and Tryk D A 2008 Surface Science Reports 63 515-582

[5] Hashimoto K, Irie H and Fujishima A 2005 Jap. J. Appl. Phys. 44(12) 8269-8285

[6] Richards B S 2004 Prog. Photovolt: Res. Appl. 12 253-281

[7] Jeong S-H, Kim, J-K, Kim B-S, Shim S-H and Lee B-T 2004 Vacuum 76 507-515

[8] Battaglin C, Caccavale F, Menelle A, Montecchi M, Nichelatti E, Nicoletti F and Polato P 1999 Thin Solid Films 351 176-179

[9] Ahn Y U, Kim E J, Kim H T and Hahn S H 2003 Materials Letters 57 4660-4666

[10] Battiston G A, Gerbasi R, Porchia M and Marigo A 1994 Thin Solid Films 239186

[11] Mergel D, Buschendorf U D, Eggert S, Grammes R and Samset B 2000 Thin Solid Films 371 218224

[12] Li C, Zheng Z, Zhang F, Yang S, Wang H, Chen L, Zhang F, Wang X and Liu X 2000 Nucl. Instr. and Methods in Phys. Res. B 169 21-25

[13] Gilo M and Croitoru N 1996 Thin Solid Films 283 84-89

[14] Meng L-J and dos Santos M P 1993 Thin Solid Films 226 22- 29

[15] Takeda S, Suzuki S, Odaka H and Hosono H 2001 Thin Solid Films 392 338-344

[16] Musil J, Herman D and Sicha J 2006 J. Vac. Sci. Technol. A 24(3) 521

[17] Martin N, Santo A M E, Sanjines R and Levy F 2001 Surface and Coatings Technol. 138 77-83

[18] Löbl P, Huppertz M and Mergel D 1994 Thin Solid Films 251 72-79

[19] Zeman P and Takabayashi S 2002 J. Vac. Sci. Technol. A 20(2) 388

[20] Song P K, Irie Y, Ohno S, Sato Y and Shigesato Y 2004 Jap. J. Appl. Phys. 43(4A) L442-L445

[21] Song P K, Irie Y, Sato Y and Shigesato Y 2004 Jap. J. Appl. Phys. 43(3A) L358-L361

[22] Okimura K 2001 Surface and Coatings Technol. 135 286-290

[23] Zeman P and Takabayashi S 2001 Surface and Coatings Technol. 153 93-99

[24] Zeman P and Takabayashi S 2003 Thin Solid Films 433 57-62

[25] Yamagishi M, Kuriki S, Song P K and Shigesato Y 2003 Thin Solid Films 442 227-231

[26] Musil J, Sicha J, Herman D and Cerstvy R 2007 J. Vac. Sci. Technol. A 25(4) 666

[27] Sicha J, Herman D, Musil J, Stryhal Z and Pavlik J 2007 Nanoscale Res. Lett. 2 123-129

[28] Sicha J, Musil J, Meissner M and Cerstvy R 2008 Applied Surface Science 254 3793-3800

[29] Zywitzki O, Modes T, Sahm H, Frach P, Goedicke K and Glöß D 2004 Surface and Coatings Technol. 180-181 538-543

[30] Glöß D, Frach P, Zywitzki O, Modes T, Klinkenberg S and Gottfried C 2005 Surface \& Coatings Technol. 200 967-971

[31] Kuzel R, Nichtova L, Herman D, Sicha J and Musil J 2007 Z. Kristallogr. Suppl. 26 241-246

[32] Kuzel R, Nichtova L, Matej Z, Herman D, Sicha J and Musil J 2007 Z. Kristallogr. Suppl. 26 247252

[33] Kuzel R, Nichtova L, Matej Z, Sicha J and Musil J 2008 Z. Kristallogr. Suppl. 27 287-294

[34] Alami J, Sarakinos K, Uslu F, Klever C, Dukwen J and Wuttig M 2009 J. Phys. D: Appl. Phys. 42 115204

[35] Konstantinidis S, Dauchot J P and Hecq M 2006 Thin Solid Films 515 1182-1186

[36] Stranak V, Cada M, Quaas M, Block S, Bogdanowicz R, Kment S, Wulff H, Hubicka Z, Helm C A, Tichy M and Hippler R 2009 J. Phys. D: Appl. Phys. 42105204

[37] Stranak V, Quaas M, Wulff H, Hubicka Z, Wrehde S, Tichy M and Hippler R 2008 J. Phys. D: Appl. Phys. 41055202

[38] Severin D, Kappertz O, Nyberg T, Berg S and Wuttig M 2007 Thin Solid Films 515(7-8) 3554-3558

[39] Severin D, Sarakinos K, Kappertz O, Pflug A and Wuttig M 2008 J. Appl. Phys. 103083306

[40] Mraz S and Schneider J M 2006 J. Appl. Phys. 100023503

[41] Mraz S and Schneider J M 2006 Appl. Phys. Lett. 89051502

[42] Richter F, Welzel T, Kleinhempel R, Dunger T, Knoth T, Dimer M and Milde F 2009 Surface \& Coatings Technol. 204 845-849

[43] Ngaruiya J M, Kappertz O, Mohamed S H and Wuttig M 2004 Appl. Phys. Lett. 85(5) 748 
[44] Leprince-Wang Y, Souche D, Yu-Zhang K, Fisson S, Vuye G and Rivory J 2000 Thin Solid Films 359 171-176

[45] Miyake S, Honda K, Kohno T, Setsuhara Y, Satou M and Chayahara A 1992 J. Vac. Sci. Technol. A 10(5) 3253

[46] Fukushima K and Yamada I 1988 J. Appl. Phys. 65(2) 619

[47] Fukushima K and Yamada I 1989 Applied Surface Science 43 32-36

[48] Leprince-Wang Y, Yu-Zhang K, Nguyen Van V, Souche D and Rivory J 1997 Thin Solid Films 307 $38-42$

[49] Miyata T, Tsukada S and Minami T 2006 Thin Solid Films 496 136-140

[50] Tominaga K, Iwamura S, Shintani Y and Tada O 1982 Jpn. J. Appl. Phys. 21(5) 688-695

[51] Tominaga K, Iwamura S, Shintani Y and Tada O 1982 Jpn. J. Appl. Phys. 21(7) 999-1002

[52] Tucek J C, Walton S G and Champion R L 1998 Surface Science 410258

[53] Mahieu S and Depla D 2007 Appl. Phys. Lett. 90121117

[54] Misina M, Bradley J W, Bäcker H, Aranda-Gonzalvo Y, Karkari S K and Forder D 2003 Vacuum 68 171-181

[55] Drese R J and Wuttig M 2006 J. Appl. Phys. 99123517

[56] Köhl D, Luysberg M and Wuttig M 2009 Phys. Status Solidi RRL 3, No. 7-8 236-238

[57] Venkataraj S, Kappertz O, Weis H, Drese R, Jayavel R and Wuttig M 2002 J. Appl. Phys. 92(7) 3599-3607

[58] O'Leary S K, Johnson S R, Lim P K 1997 J. Appl. Phys. 82(7) 3334

[59] Theiss W 2007 Hard- and Software for Optical Spectroscopy

[60] Cullity B D, Elements of X-ray Diffraction, Addison-Wesley, Reading, MA, 2nd edn., 1978

[61] Sarakinos K, Alami J and Wuttig M 2007 J. Phys. D: Appl. Phys. 40 2108-2114

[62] Christie D J 2005 J. Vac. Sci. Technol. A 23(2) 330

[63] Sarakinos K, Alami J, Dukwen J, Woerdenweber J and Wuttig M 2008 J. Phys. D: Appl. Phys. 41 215301

[64] Alami J, Sarakinos K, Mark G and Wuttig M 2006 Appl. Phys. Lett. 89154104

Figures 


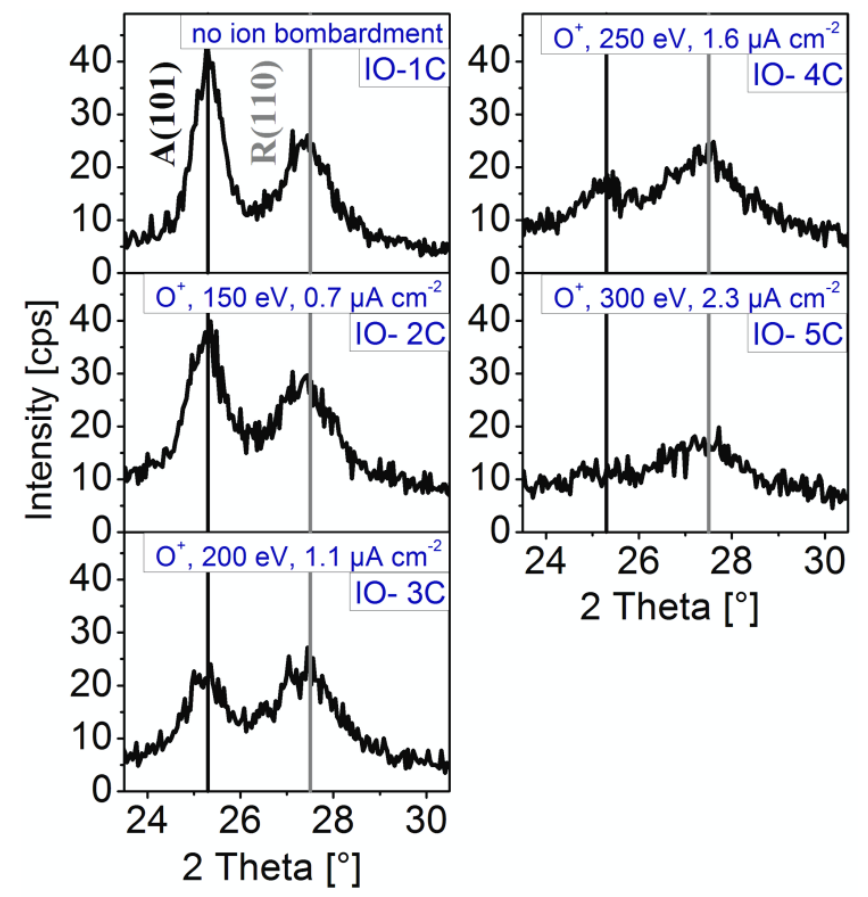

Figure 1. Grazing incidence XRD spectra of $\mathrm{TiO}_{2}$ films sputtered at high oxygen flow under additional $\mathrm{O}^{+}$ ion bombardment with different energies and intensities. The impact of energetic bombardment leads to a selective degradation of the anatase phase. However, at very intense bombardment also the rutile phase deteriorates.

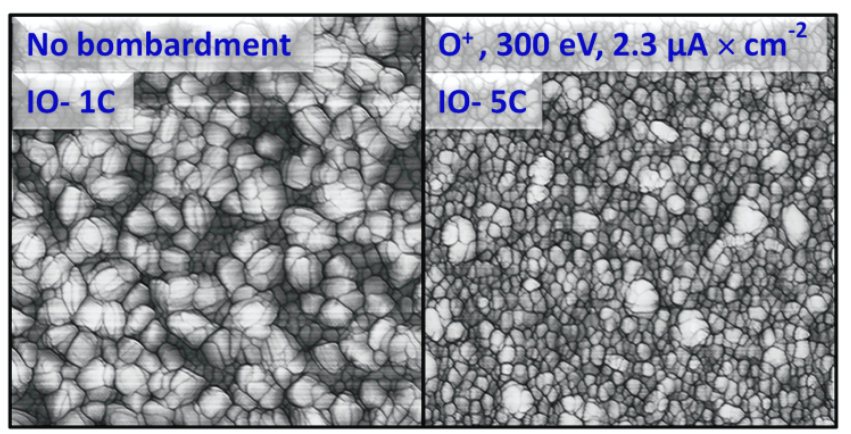

Figure 2. Surface topography of a $\mathrm{TiO}_{2}$ film bombarded with $\mathrm{O}^{+}$ions. XRD spectra of these films are shown in figure 1 . The left image shows the un-bombarded reference which features a mixed type 1 and type 2 structure. The sample grown under intense ion bombardment is characterized by a pure type 1 surface structure. The scan size is $1 \mu \mathrm{m} \times 1 \mu \mathrm{m}$. Images are post-processed to enhance surface corrugation.
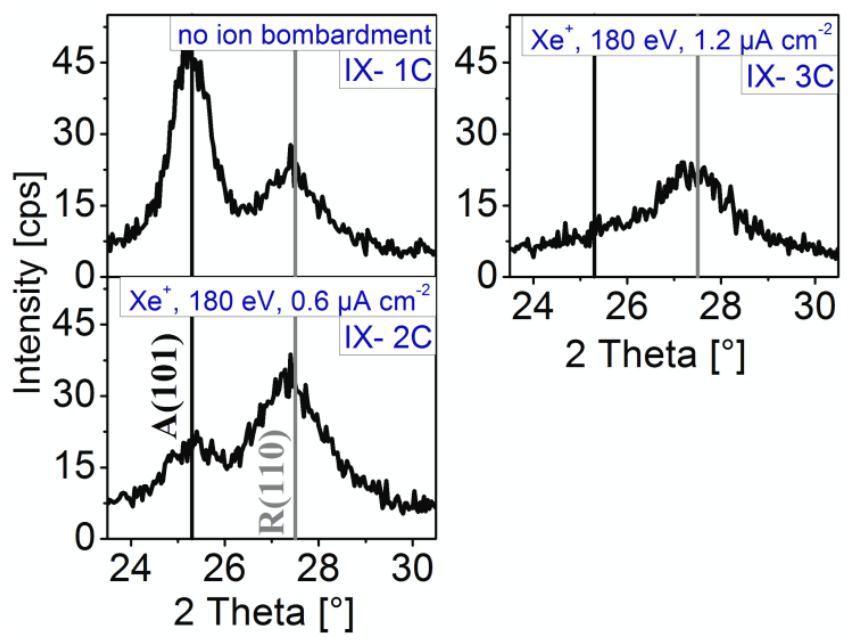

Figure 3. Grazing incidence XRD spectra of $\mathrm{TiO}_{2}$ films sputtered at high oxygen flow under additional $\mathrm{Xe}^{+}$ ion bombardment with two different intensities at a fixed ion energy of $180 \mathrm{eV}$. The impact of energetic 
bombardment leads to a selective degradation of the anatase phase. At small currents of the auxiliary $\mathrm{Xe}^{+}$ion bombardment the growth of the rutile phase is promoted by the bombardment.

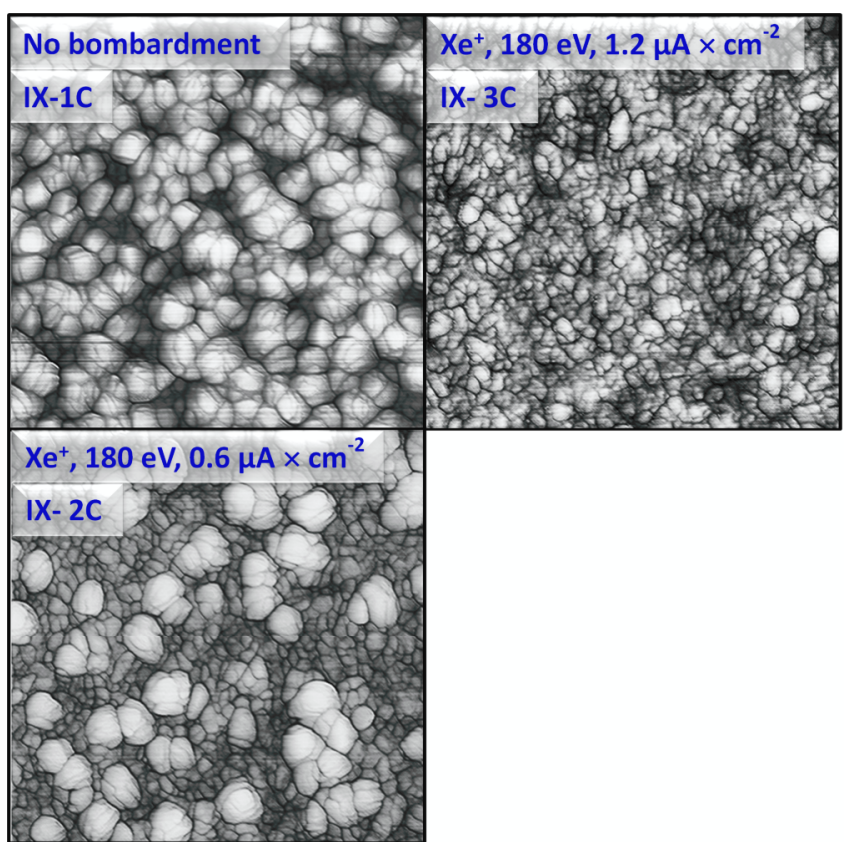

Figure 4. Surface topography of $\mathrm{TiO}_{2}$ films bombarded with $\mathrm{Xe}^{+}$ions. XRD spectra of these films are shown in figure 3. The un-bombarded reference features a mixed type 1 and type 2 structure with strong tendency to a pure type 2 structure. Under medium intensity bombardment the type 2 content is significantly reduced while the sample grown under intense ion bombardment is characterized by a pure type 1 surface structure. The scan size is $1 \mu \mathrm{m} \times 1 \mu \mathrm{m}$. Images are post-processed to enhance surface corrugation.

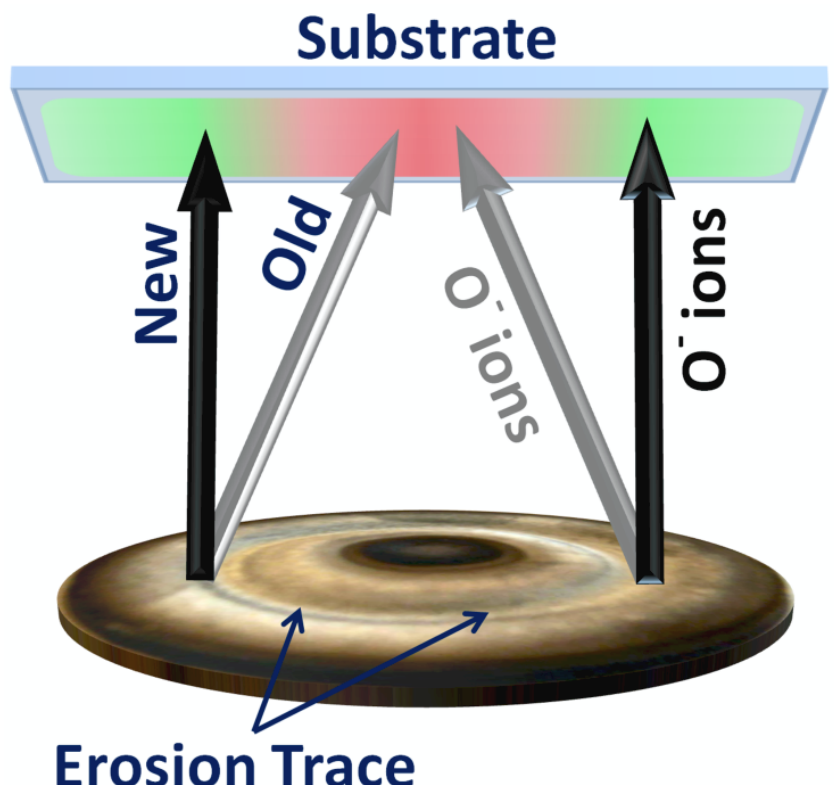

Figure 5. Influence of racetrack geometry on the ion trajectories for new and old targets. Oxygen ions that are created at the target are accelerated in a direction perpendicular to the local target surface area. For new targets the ions are accelerated towards substrate position directly opposite of the erosion trace. For aged targets the distribution of ion trajectories strongly depends on the shape of the erosion trace, which typically results in bombardment predominantly of the sample centre in the coating systems utilized for the present work [cf 38]. 


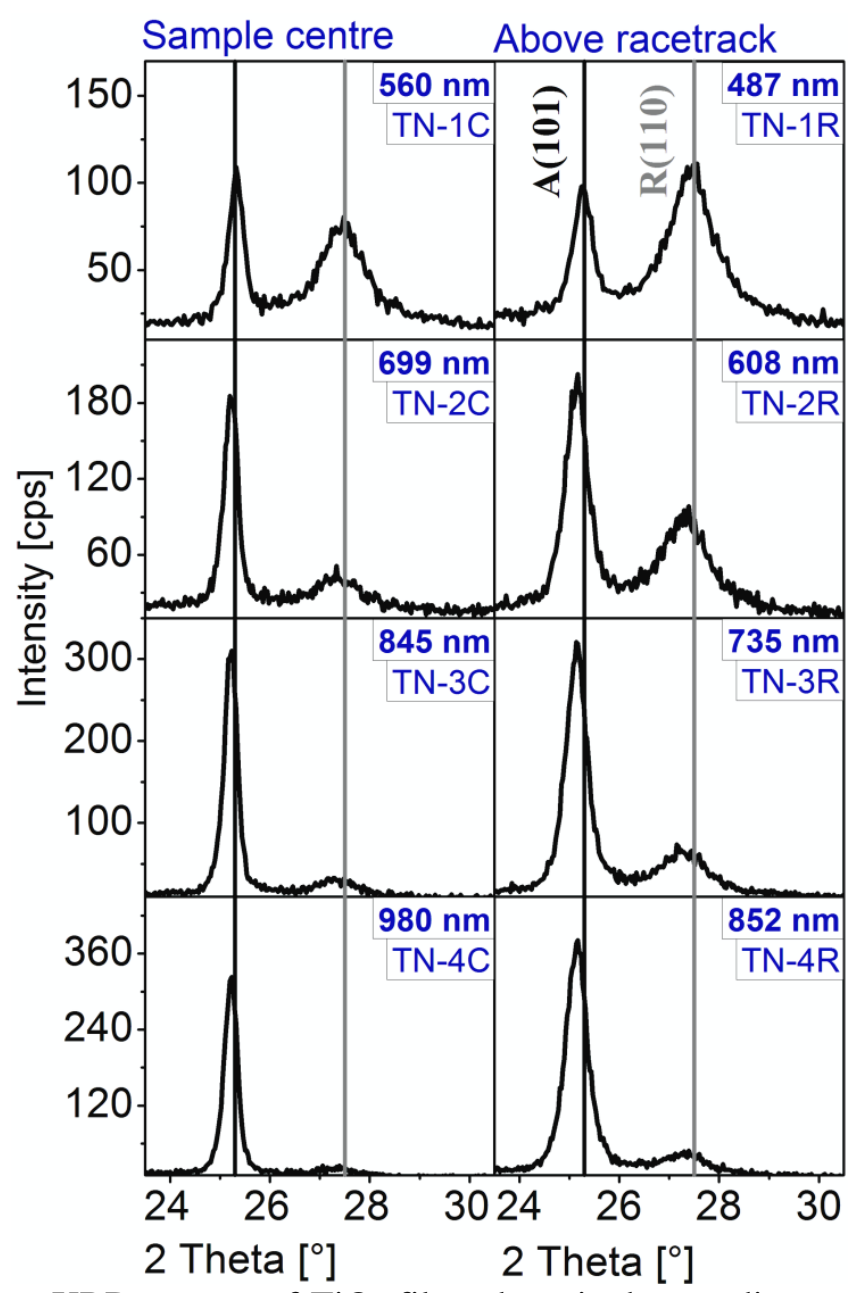

Figure 6. Grazing Incidence XRD spectra of $\mathrm{TiO}_{2}$ films deposited at medium oxygen flow utilizing a new target. At positions above the target's racetrack the rutile phase is more dominant as compared to the sample centre. Also, the anatase peak shows a larger FWHM and a small shift towards lower angles compared to the centre, which is indicative of a smaller average grain size and increased compressive stress, respectively.

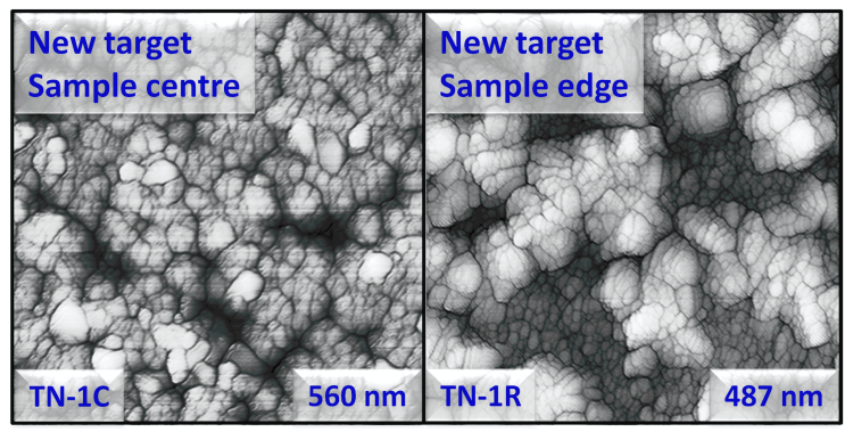

Figure 7. Surface topography of a $\mathrm{TiO}_{2}$ film deposited using a new target. Above the target's racetrack (sample edge) the surface features a mixed type 1 and type 2 structure. At the sample centre a closed type 1 structure appears to dominate the surface. Corresponding XRD spectra of this sample are shown in figure 6. The scan size is $1 \mu \mathrm{m} \times 1 \mu \mathrm{m}$. Images are post-processed to enhance surface corrugation. 


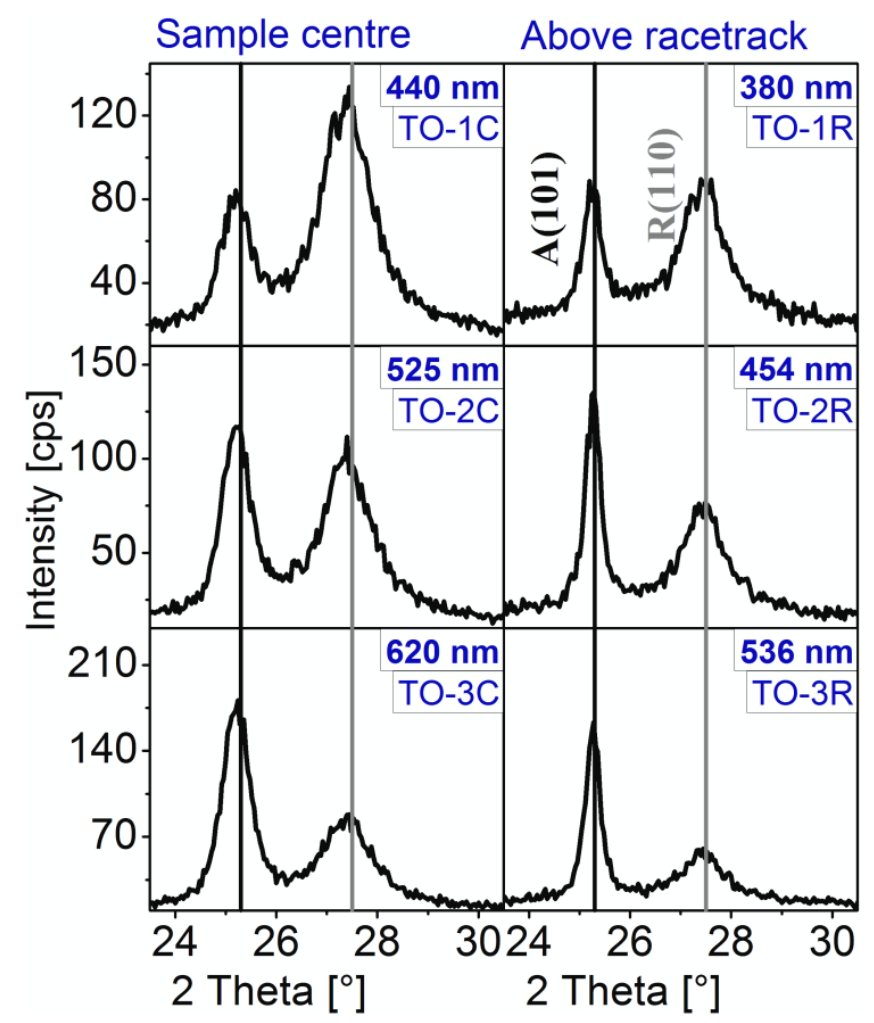

Figure 8. Grazing Incidence XRD spectra of $\mathrm{TiO}_{2}$ thin films deposited at medium oxygen flow from an old target. The samples were scanned at the sample centre and at positions directly above the target's racetrack, respectively. In the sample centre the rutile phase is more pronounced compared to the position above the racetrack. Also, the anatase peak shows a small shift towards lower angles at the centre position in comparison. The increasing width of the anatase peak indicates that the average anatase grain size is smaller at the substrate centre.

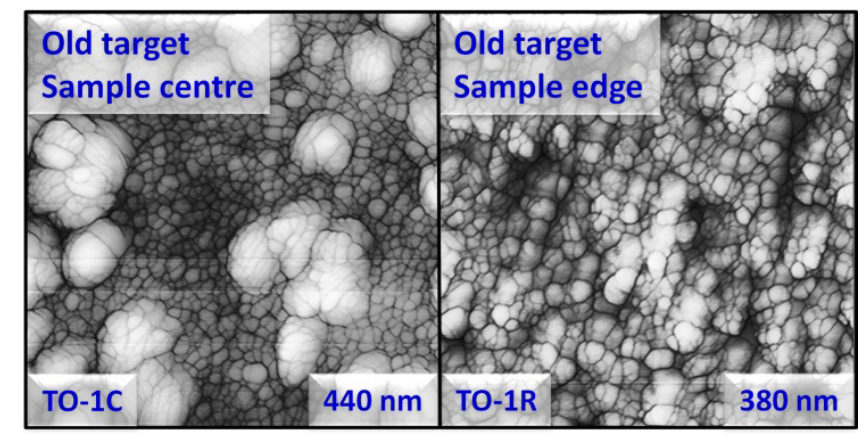

Figure 9. Surface topography of a $\mathrm{TiO}_{2}$ film deposited from an old target. Above the racetrack, the surface exhibits a closed type 2 structure while at the sample centre a mixed type 1 and type 2 structure is found. These findings correlate to the XRD spectra of this sample as shown in figure 8 . The scan size is $1 \mu \mathrm{m} \times 1$ $\mu \mathrm{m}$. Images are post-processed to enhance surface corrugation. 


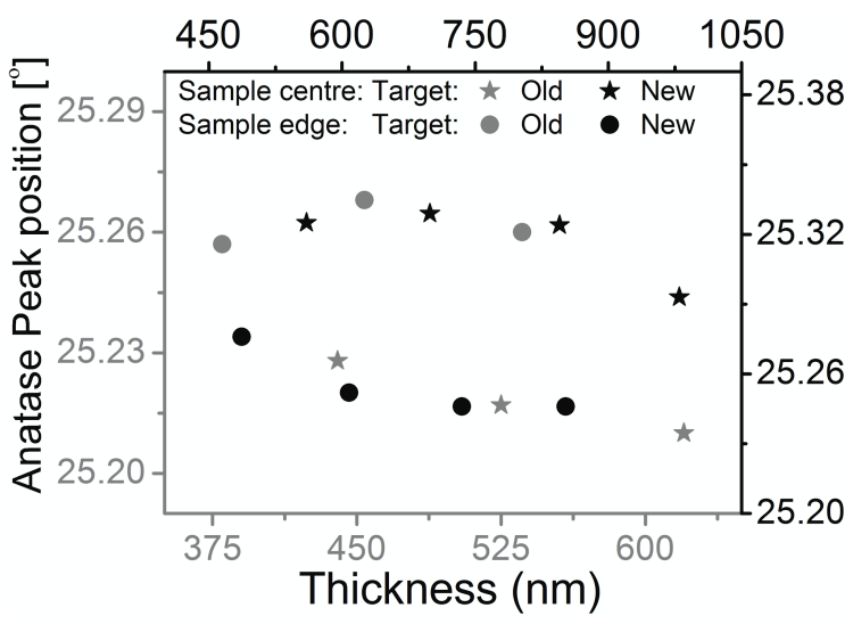

Figure 10. Position of the anatase (101) peak as extracted from the spectra shown in figures 6 and 8 . There is evidence that at sample positions subject to increased energetic oxygen ion bombardment there is a shift of the anatase peak position towards lower angles. For the new sample this is at the position opposite to the racetrack (sample edge) while for the old target this is at the sample centre. The shift of peak position indicates lattice strain and therefore mechanical film stresses induced by the impact of ions.

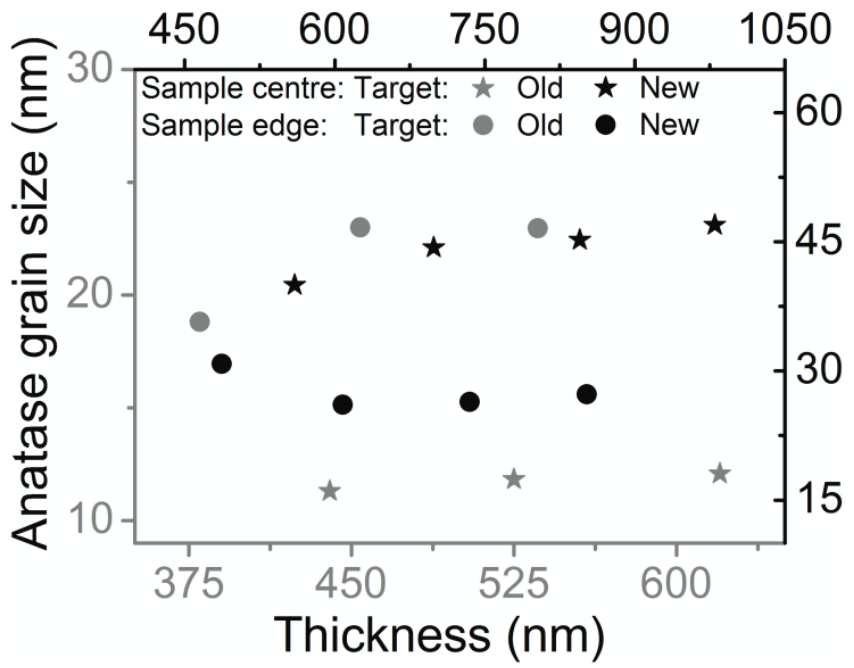

Figure 11. Estimation of the average grain sizes of the anatase phase for films sputtered from an old and a new target respectively. The Scherrer formula has been applied to the anatase peaks in the diffraction patterns shown in figures 6 and 8. For the new target, the grain size is larger at the centre of the substrate while for the old targets the grain size is largest at position at the sample edge (above the targets racetrack). This difference between the old and the new target is clear evidence for the effect of oxygen ion bombardment on structure evolution. 


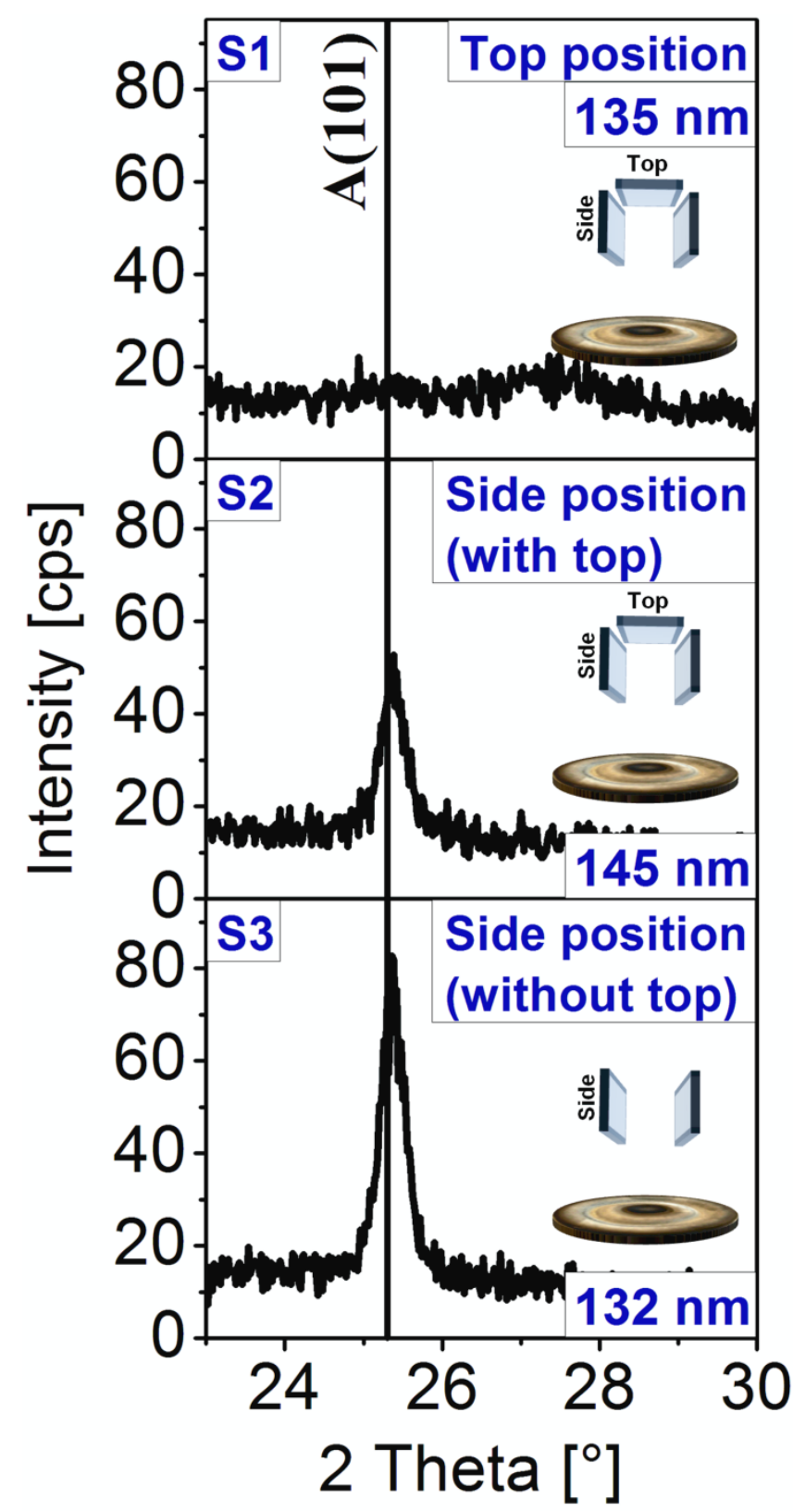

Figure 12. Grazing incidence XRD spectra of samples deposited at high oxygen flow with a special substrate geometry. To reduce the impact of energetic oxygen ions, samples have been arranged vertically at the edge of the substrate carrier. At one of the carrier positions an additional substrate (S1) had been placed at the top position. The structure of this sample is massively influenced by the oxygen ion impact and shows a very weak rutile structure probably, while sample $\mathrm{S} 2$ shows a distinct anatase structure as ion bombardment was of reduced intensity and occurred under grazing incidence. Probably sample S2 was hit by recoil ions from the top position (S1) because the structure of sample S3 which was sputtered with an open top position is of even better quality. 


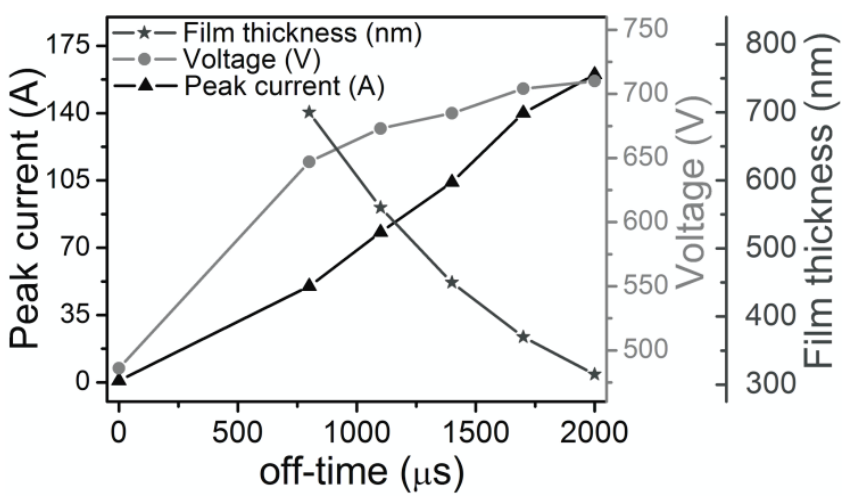

Figure 13. Process properties of $\mathrm{TiO}_{2}$ films deposited by HiPIMS. With increasing off-time (i.e. decreasing pulse frequency) at constant average target current of $900 \mathrm{~mA}$ the peak current strongly increases up to 160 amperes for the largest off-time. At the same time the target voltage increases by about $50 \mathrm{~V}$ from approximately 650 to $700 \mathrm{~V}$. The voltage in a dcMS process is only $500 \mathrm{~V}$. The deposition rate strongly decreases with increasing peak power which is evident from the resulting film thicknesses. This is a typical feature of HiPIMS processes.

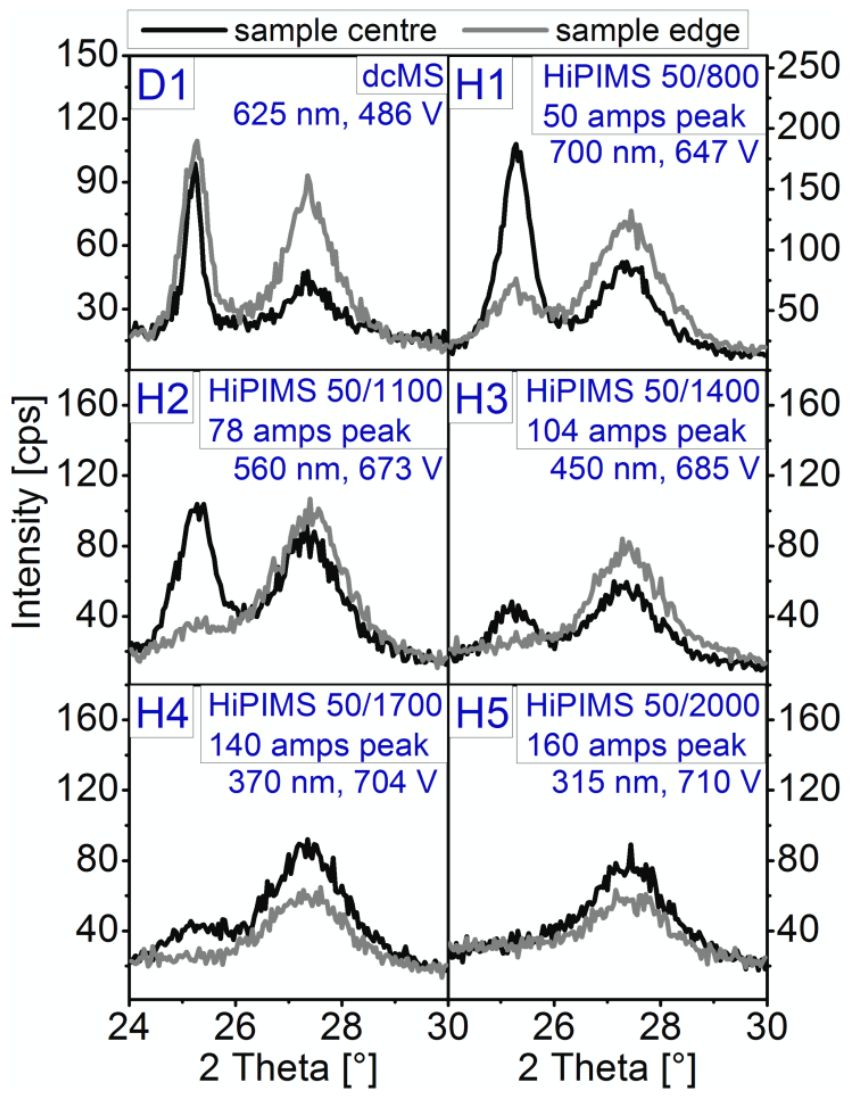

Figure 14. Grazing incidence XRD spectra of films sputtered at low oxygen flow in a HiPIMS process. The length of the voltage pulses was fixed at $50 \mu$ s for each film while the pulsing frequency was varied by changing the delay between adjacent pulses from 800 to $2000 \mu \mathrm{s}$. The discharge current was fixed at $900 \mathrm{~mA}$ for all films. Low frequencies result in larger peak sputter currents and higher discharge voltages, as indicated. The deposition time for each film was 1 hour. The film thickness especially at large pulsing frequencies is slightly increased compared to the dcMS film (D1) which serves as a reference here. The increase of the deposition rate for high frequencies (H1) is a general feature of the HiPIMS discharge and is observed for other materials as well. With increasing peak current the anatase peak selectively deteriorates while the growth of the rutile structure is promoted. At highest peak currents (H5) the structure exhibits a homogeneous profile along the substrate since no difference between the sample centre and the edge is observed. 


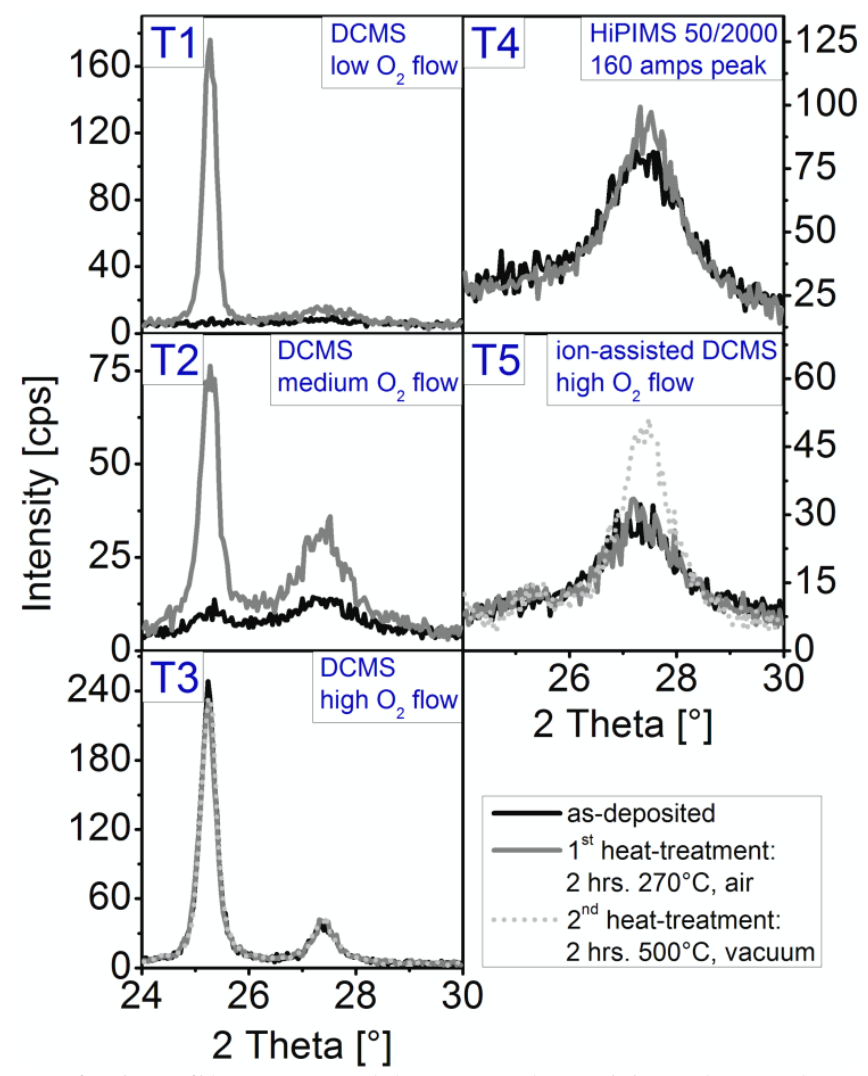

Figure 15. GI-XRD spectra of $\mathrm{TiO}_{2}$ films treated by post-deposition thermal annealing steps. Sample $\mathrm{T} 1$ T3 have been deposited in a standard dcMS process at different oxygen partial pressures. Low partial pressures yield an almost amorphous structure (T1), while with increasing partial pressure mixed rutile/anatase (T2) and finally strongly anatase films (T3) are fabricated. Samples T4 and T5 have been produced by HiPIMS and ion-assisted dcMS, respectively. Films have been annealed in air at $270{ }^{\circ} \mathrm{C}$ for 2 hours. Some films have been heated again at $500{ }^{\circ} \mathrm{C}$ for 2 hours in vacuum. For standard dcMS only the anatase sample (T3) is stable under the thermal treatment while both samples produced via ionized PVD (T4 and T5) exhibit a stable rutile phase. 


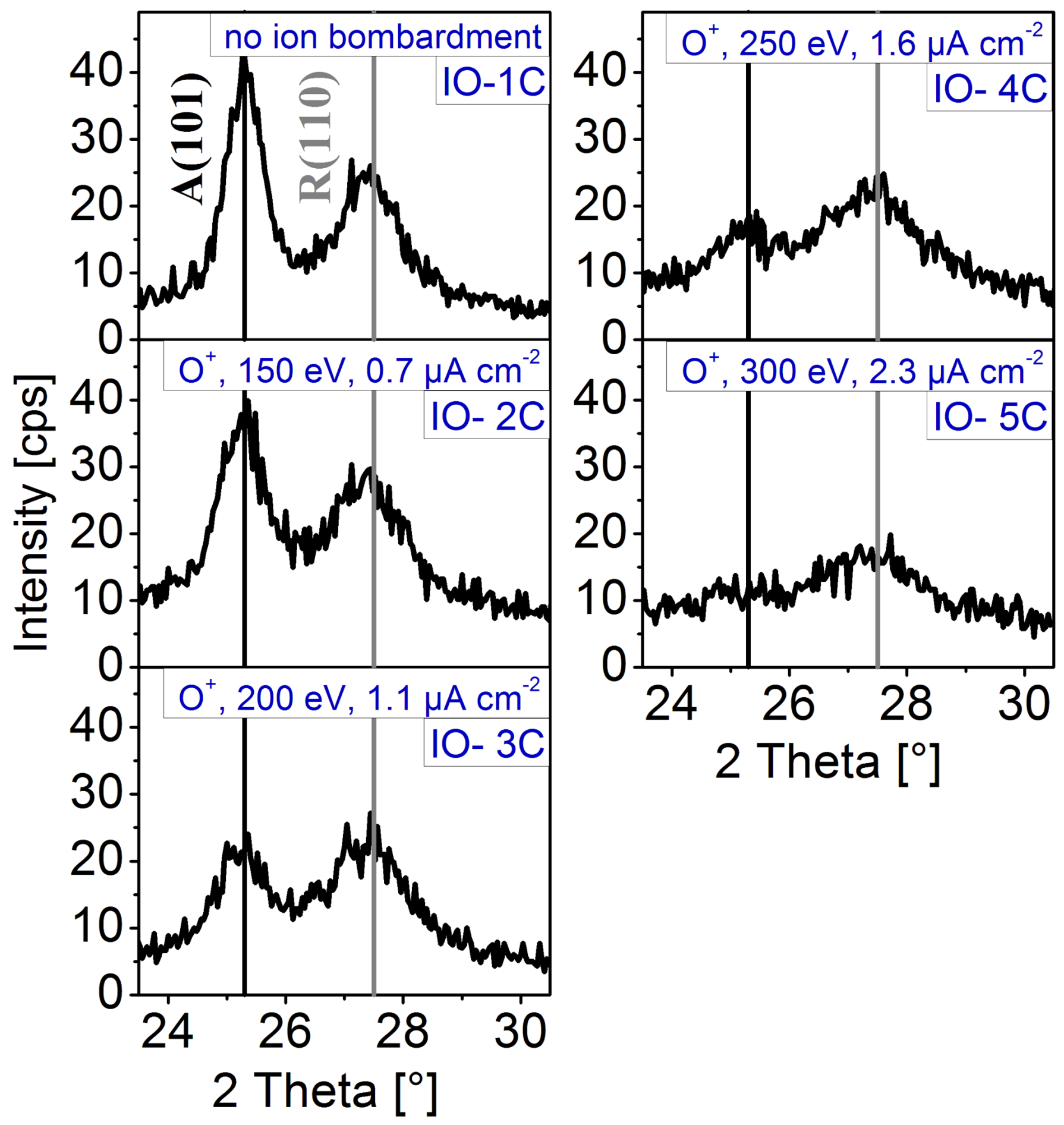

Figure 1 (Figure_1.tif) 


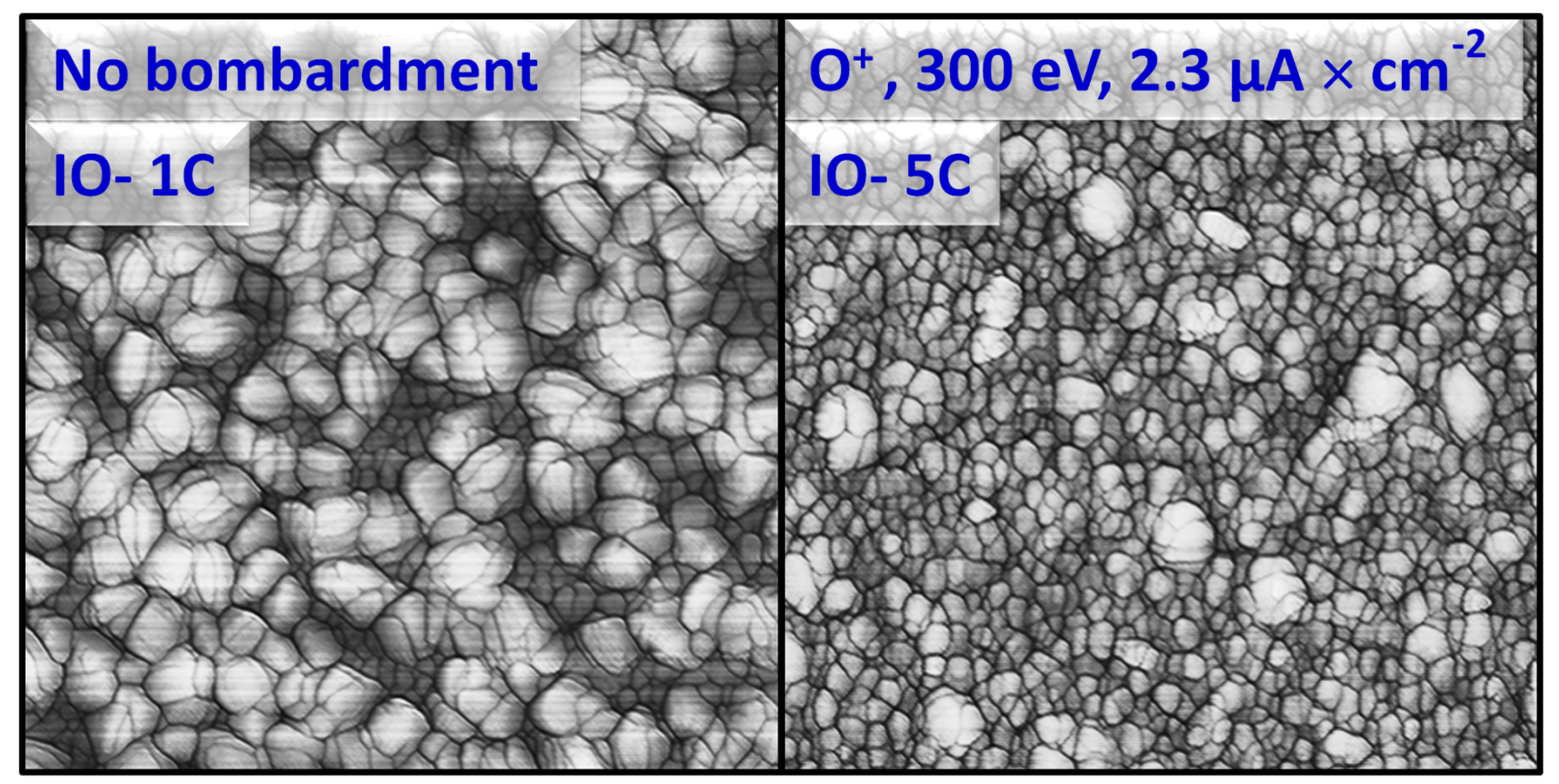

Figure 2 (Figure_2.tif) 


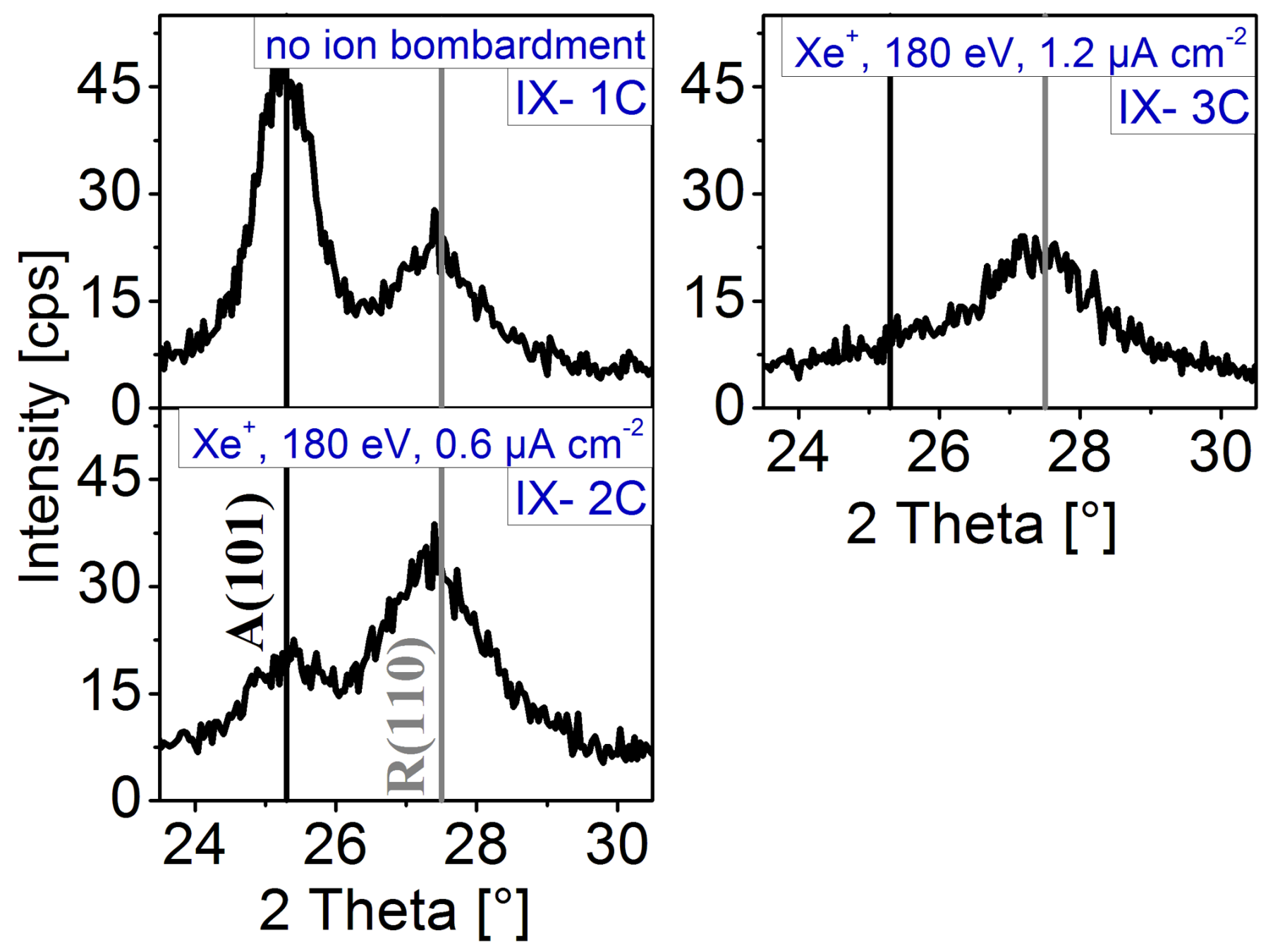

Figure 3 (Figure_3.tif) 


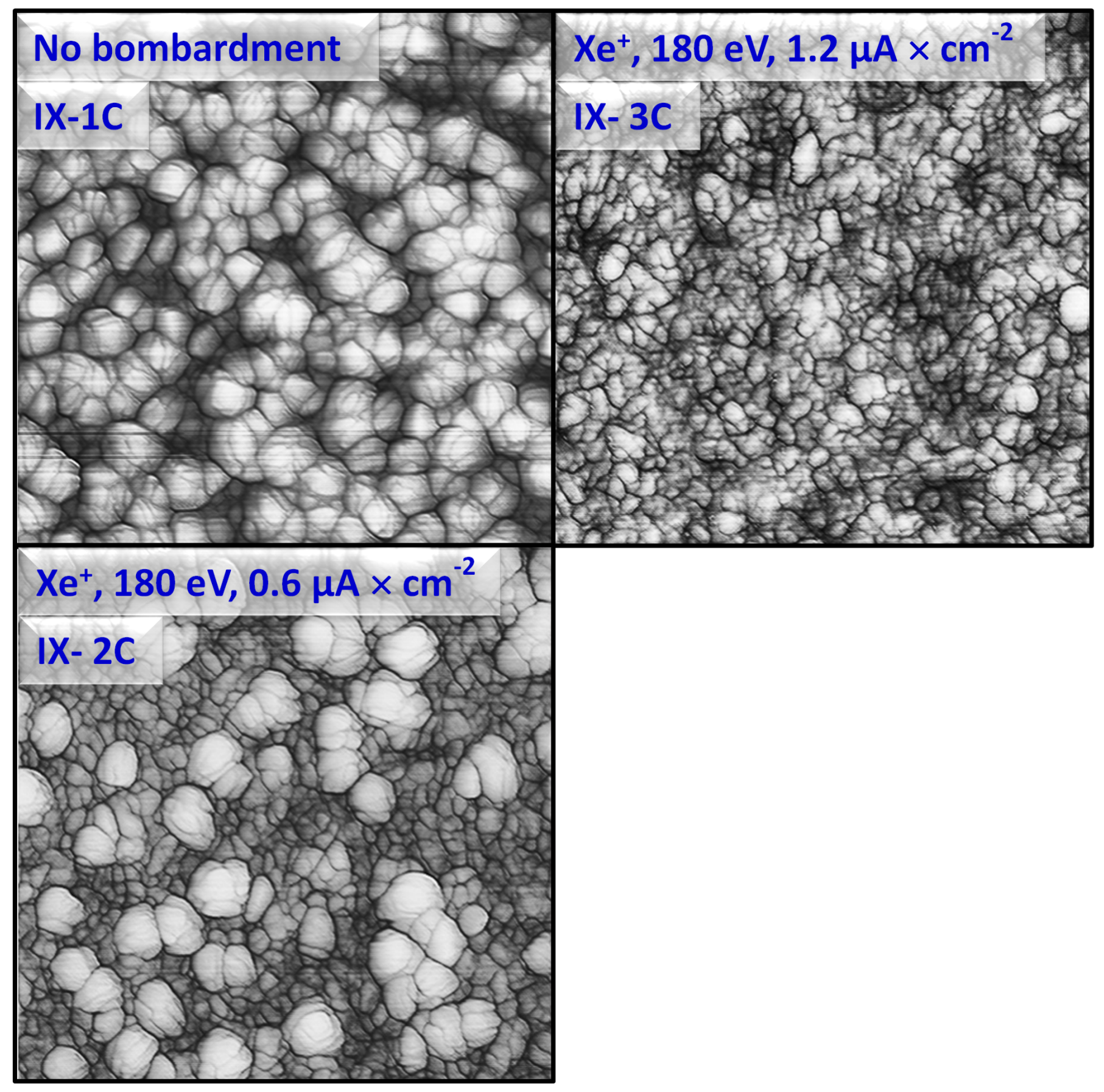

Figure 4 (Figure_4.tif) 


\section{Substrate}

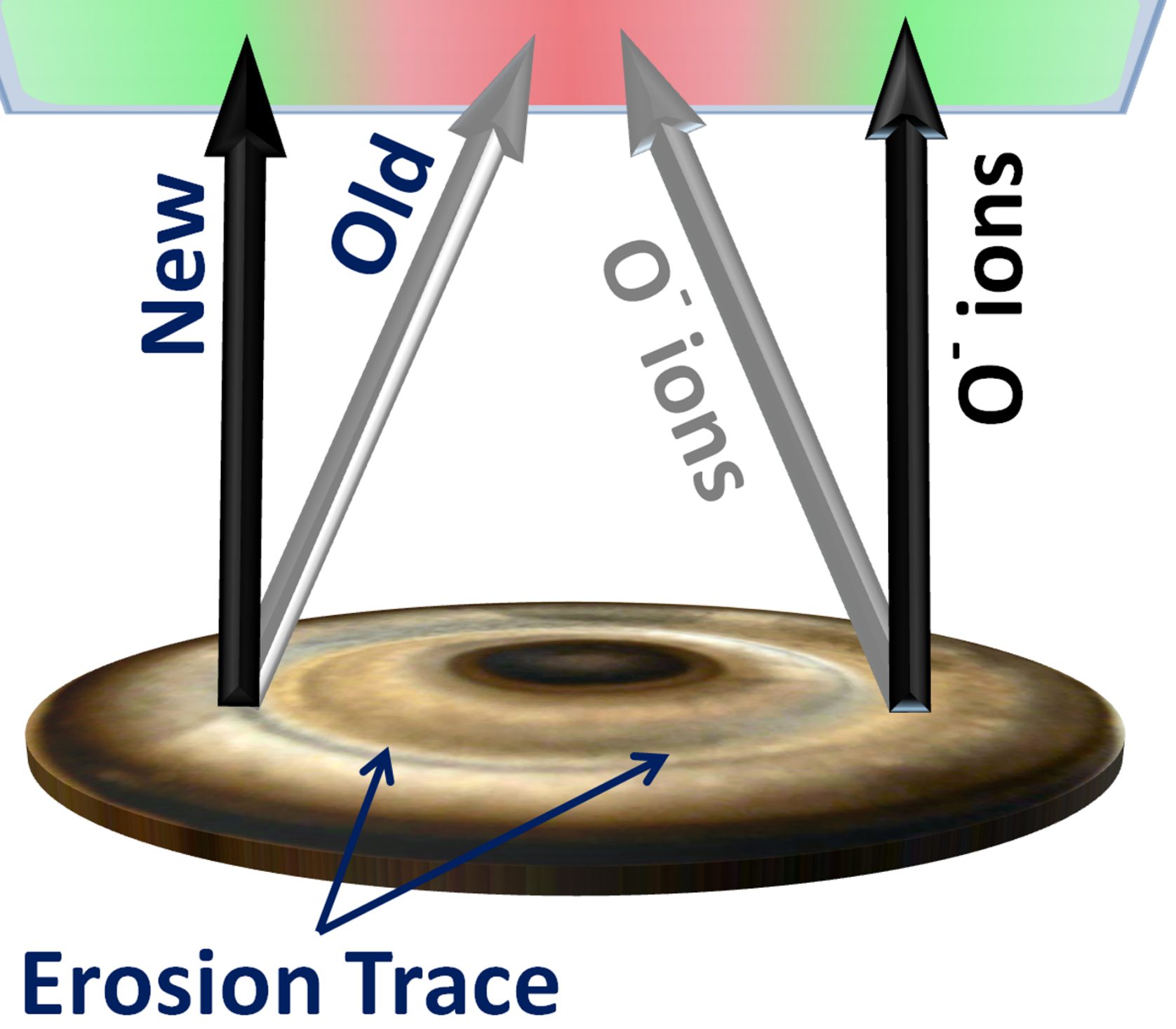

Figure 5 (Figure_5.tif) 


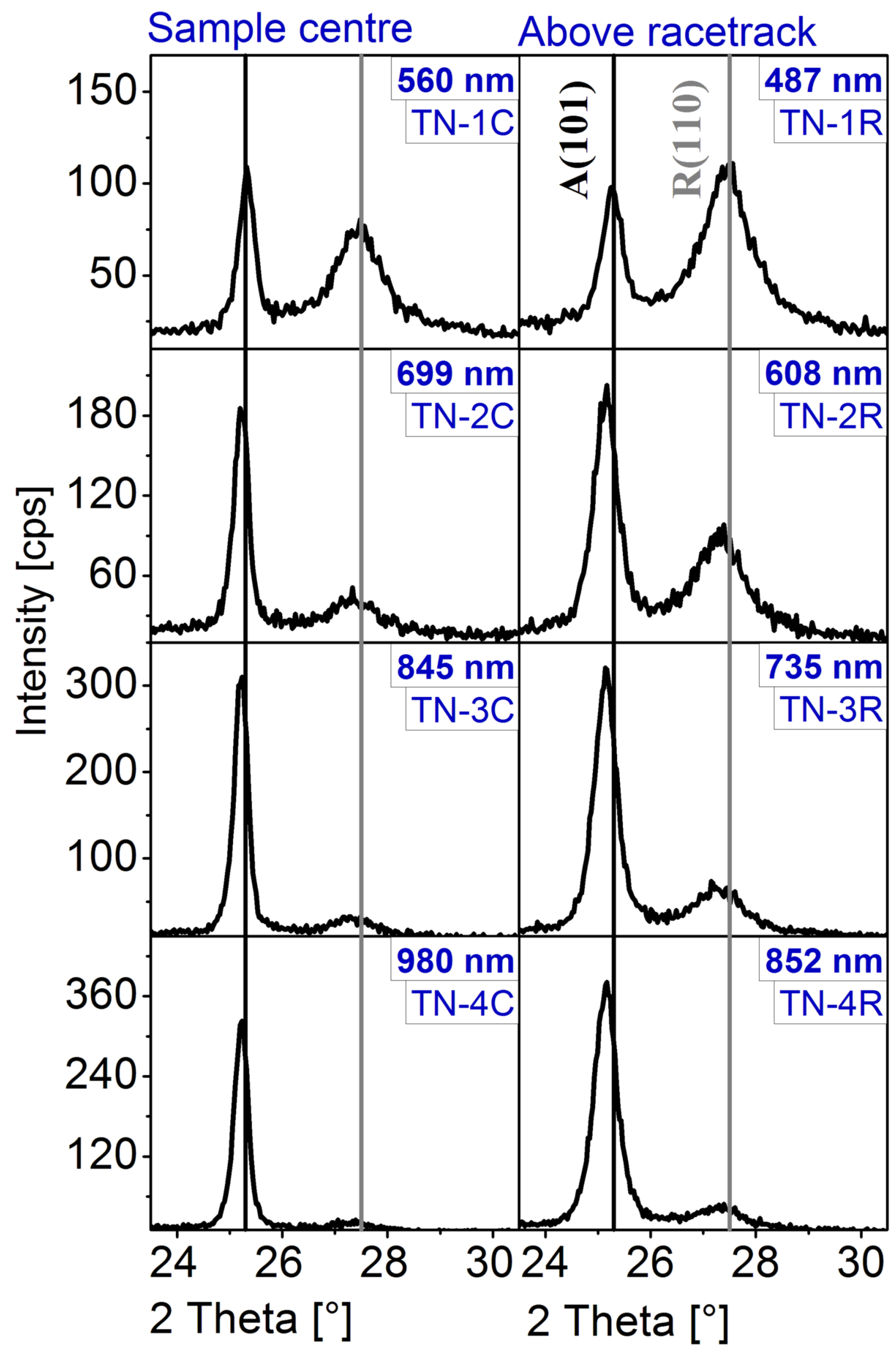

Figure 6 (Figure_6.tif) 


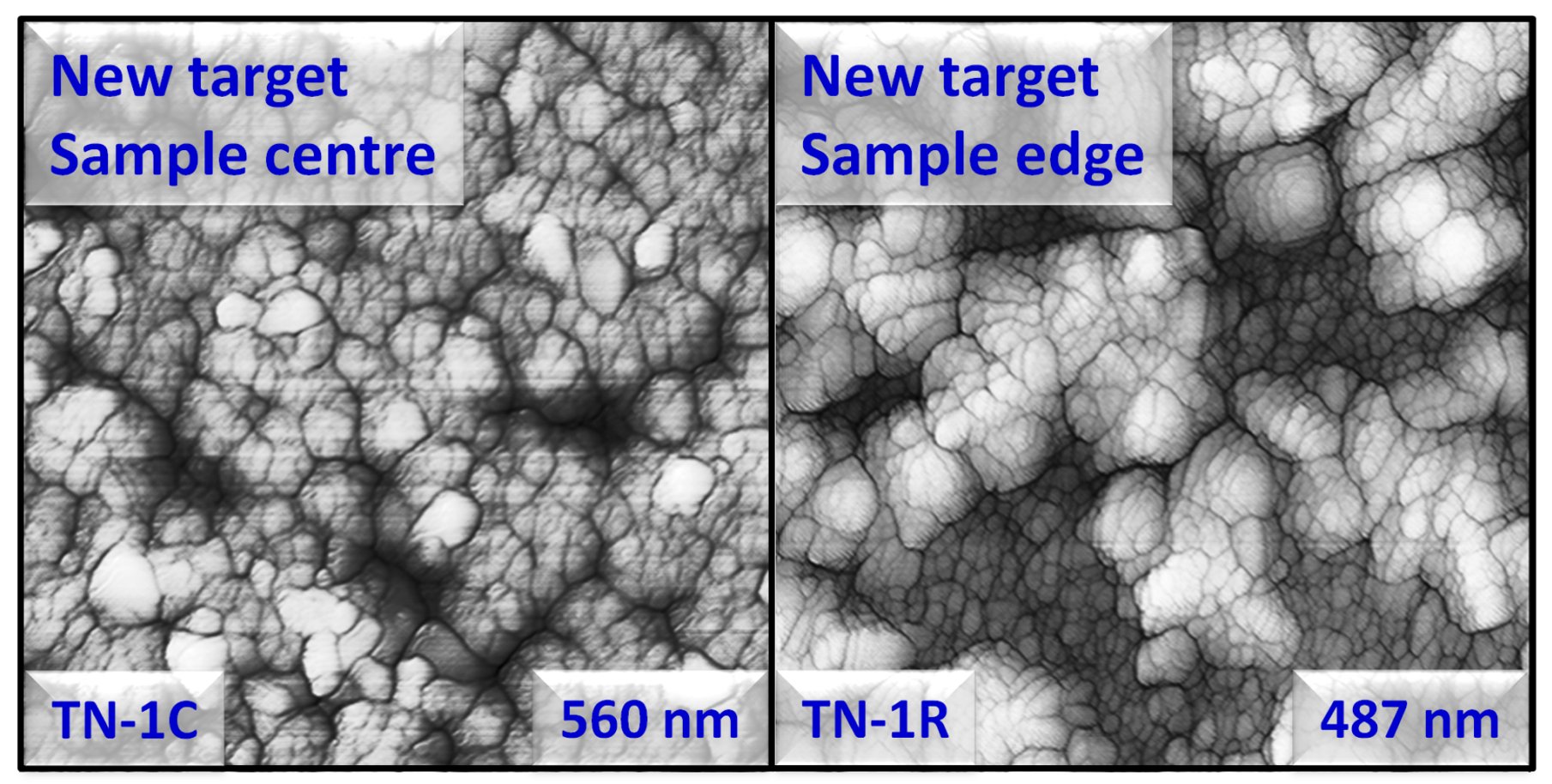

Figure 7 (Figure_7.tif) 
Sample centre

Above racetrack

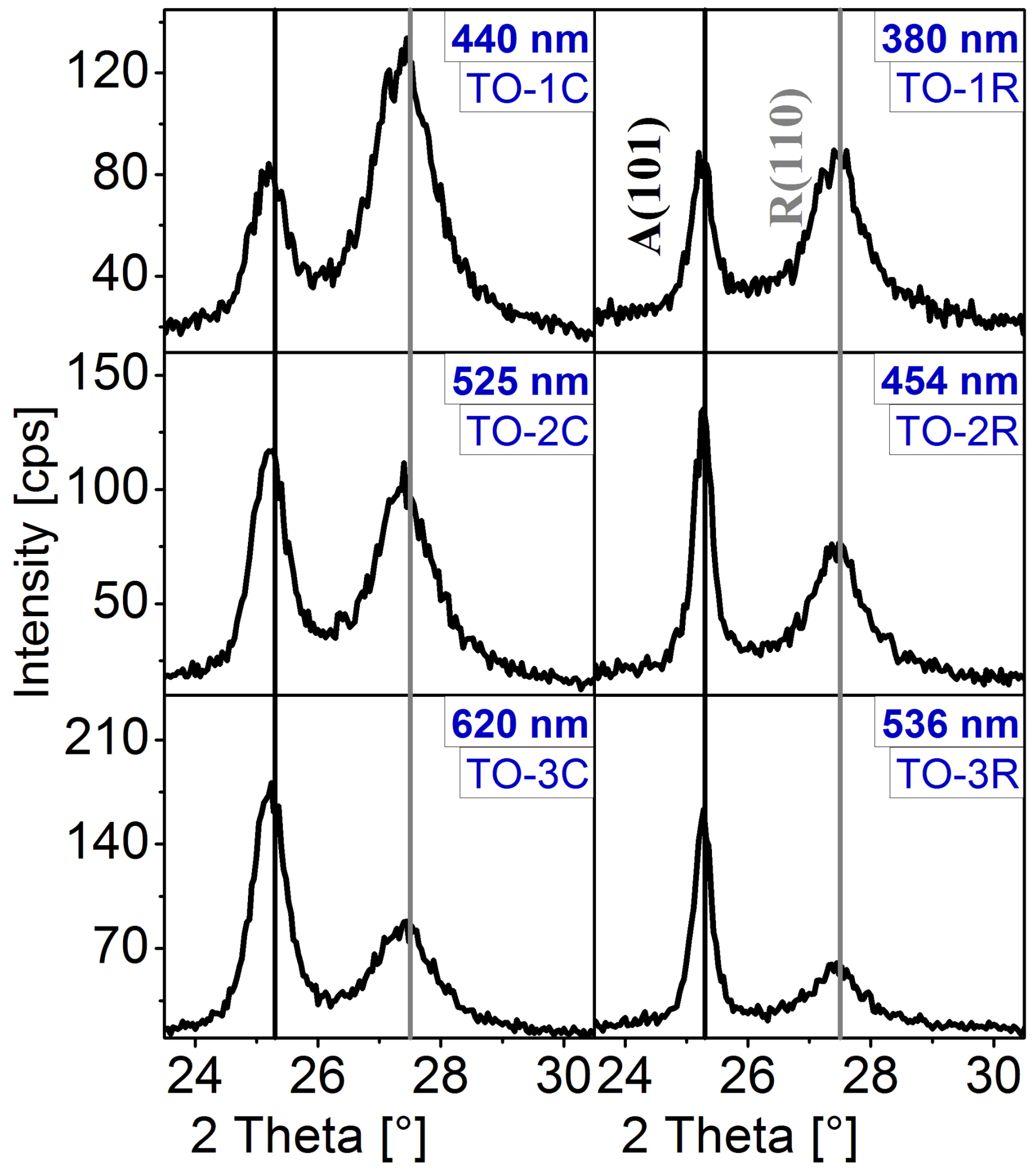

Figure 8 (Figure_8.tif) 


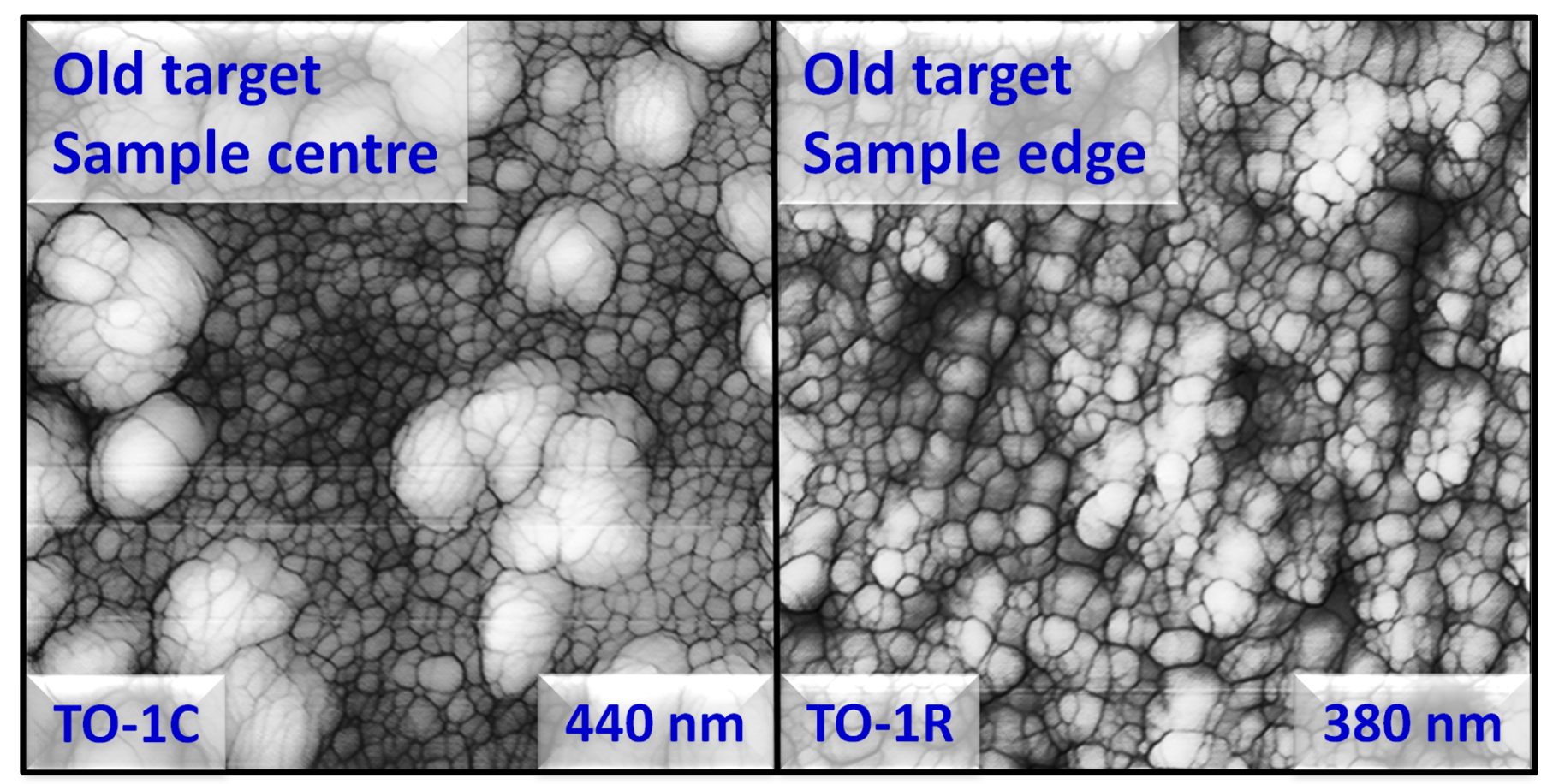

Figure 9 (Figure_9.tif) 


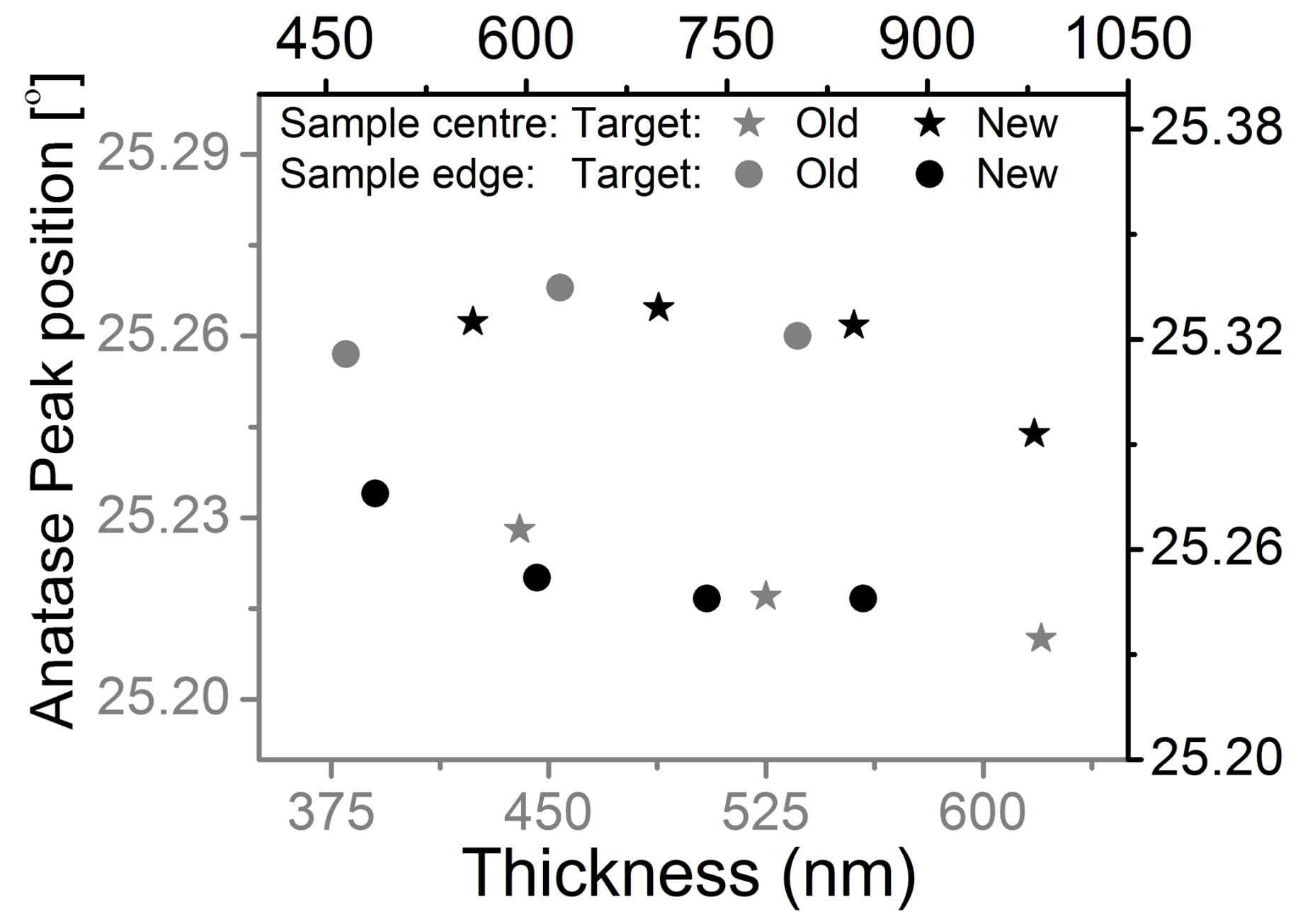

Figure 10 (Figure_10.tif) 


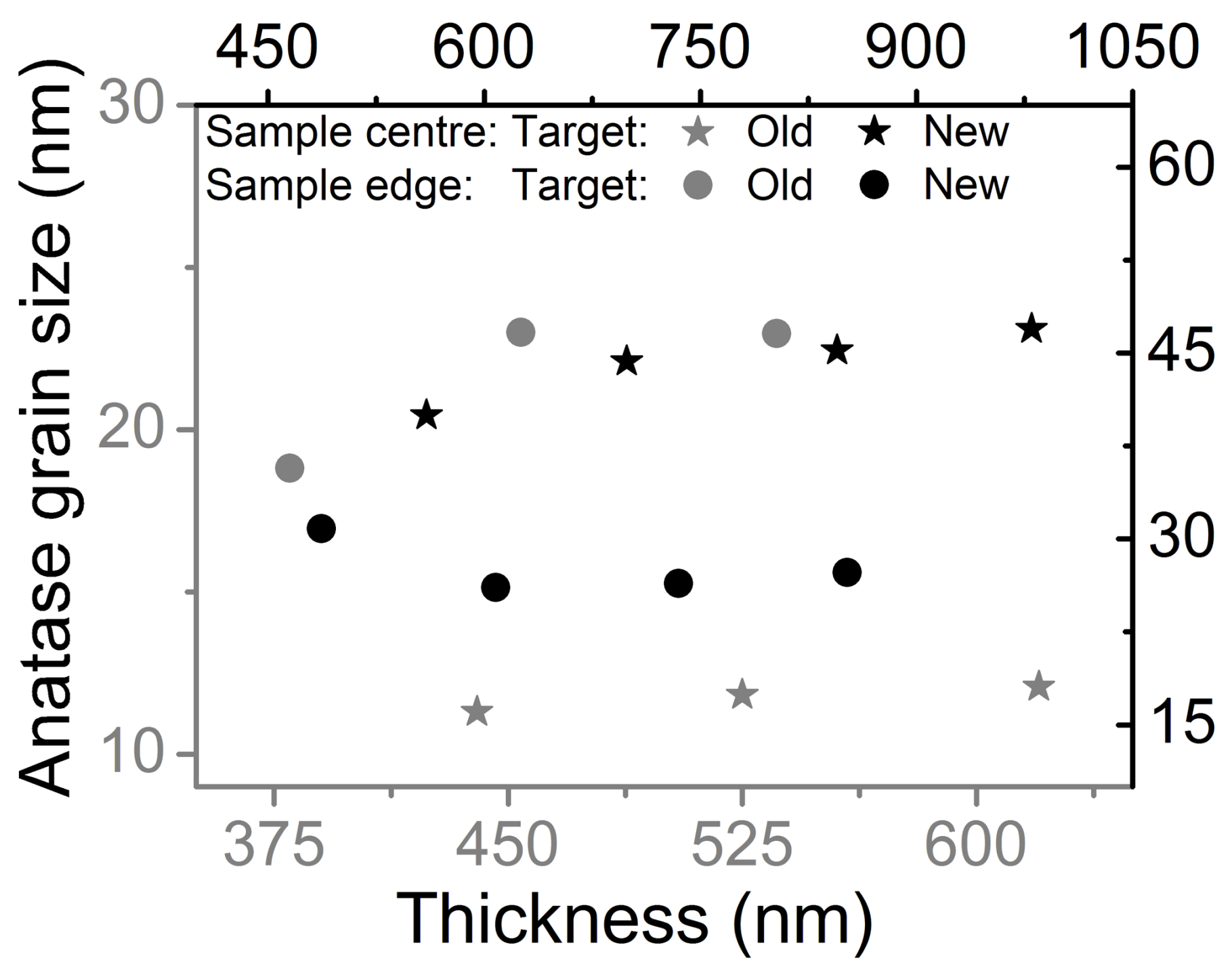

Figure 11 (Figure_11.tif) 


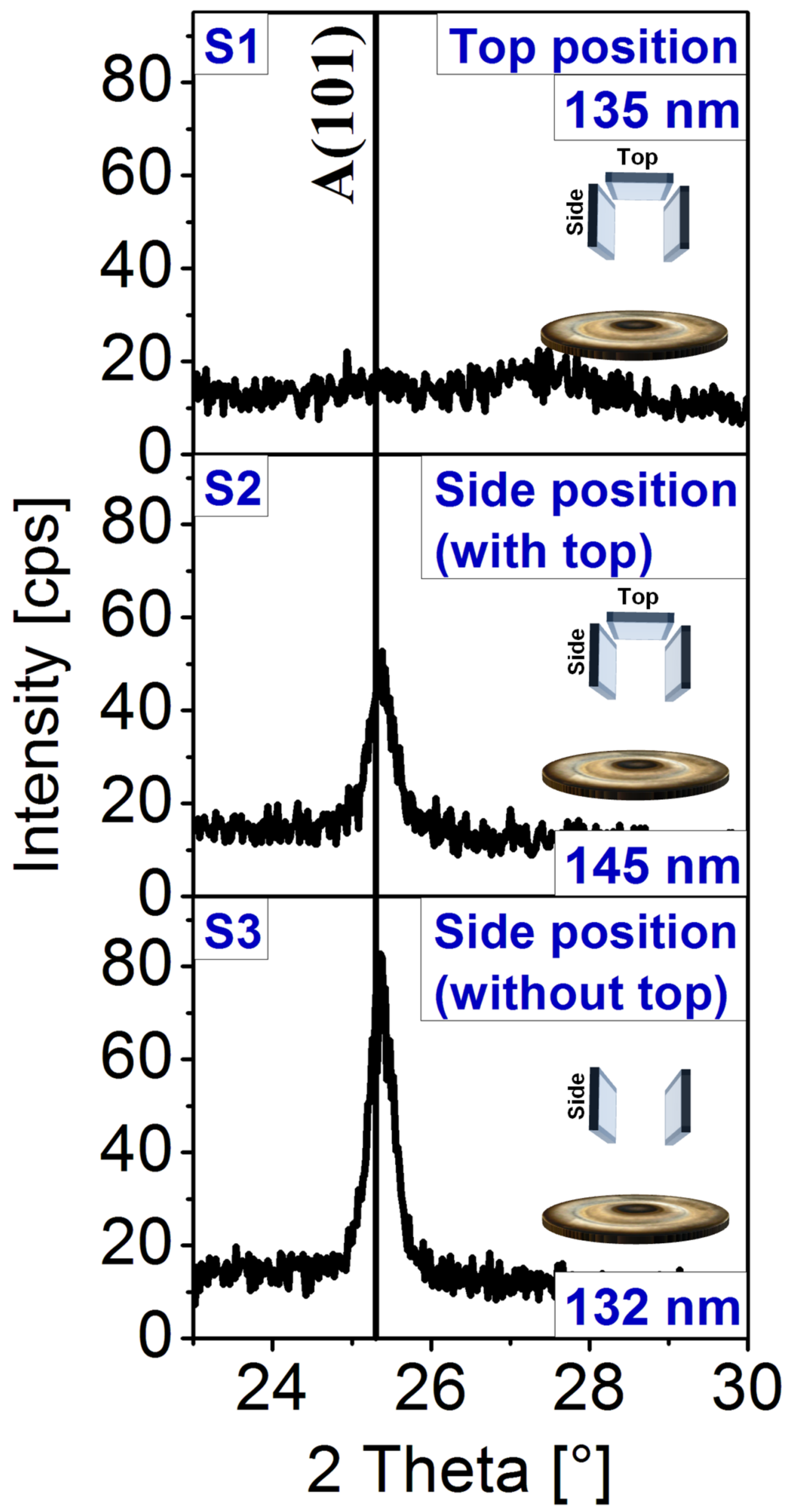

Figure 12 (Figure_12.tif) 


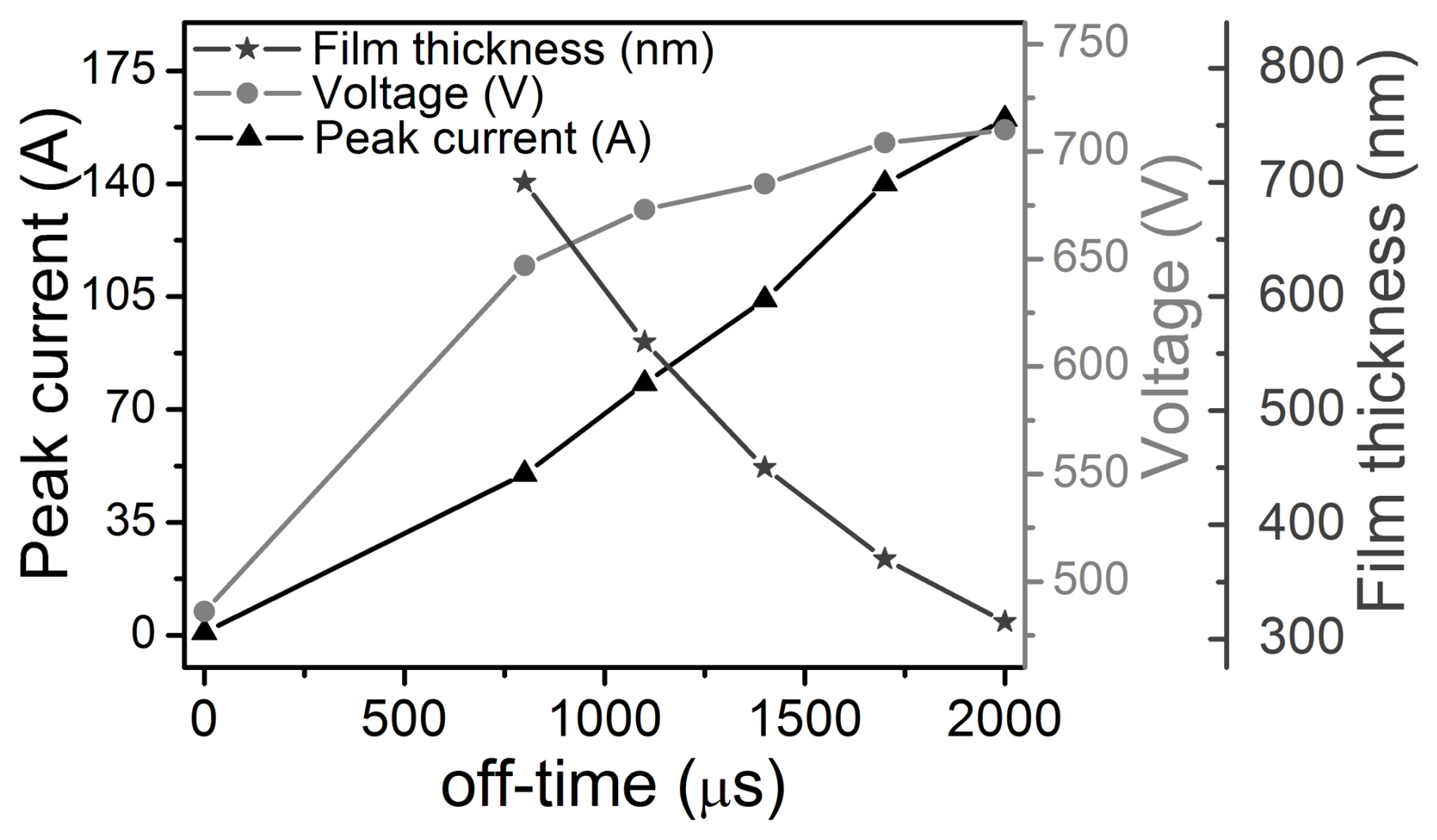

Figure 13 (Figure_13.tif) 


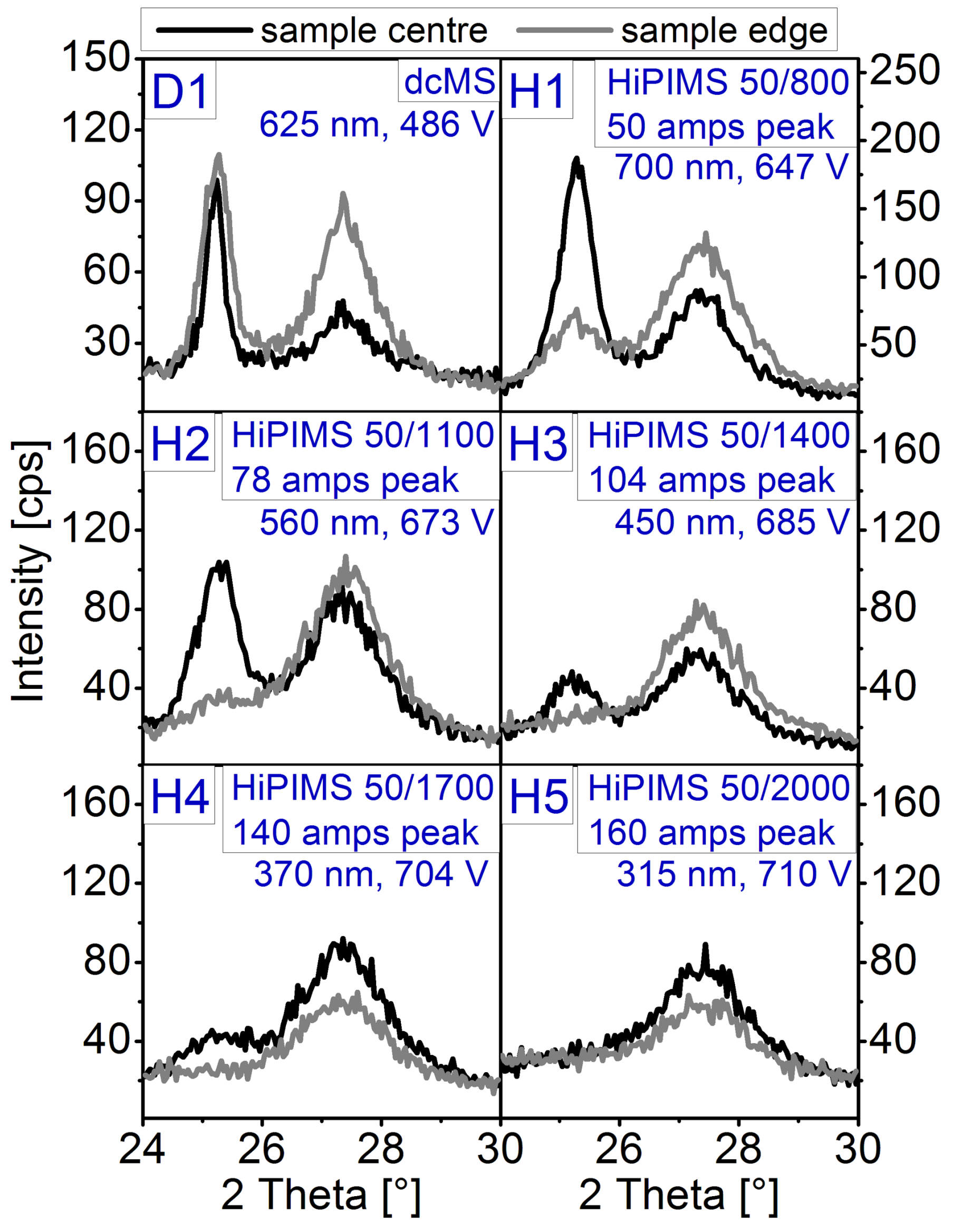

Figure 14 (Figure_14.tif) 


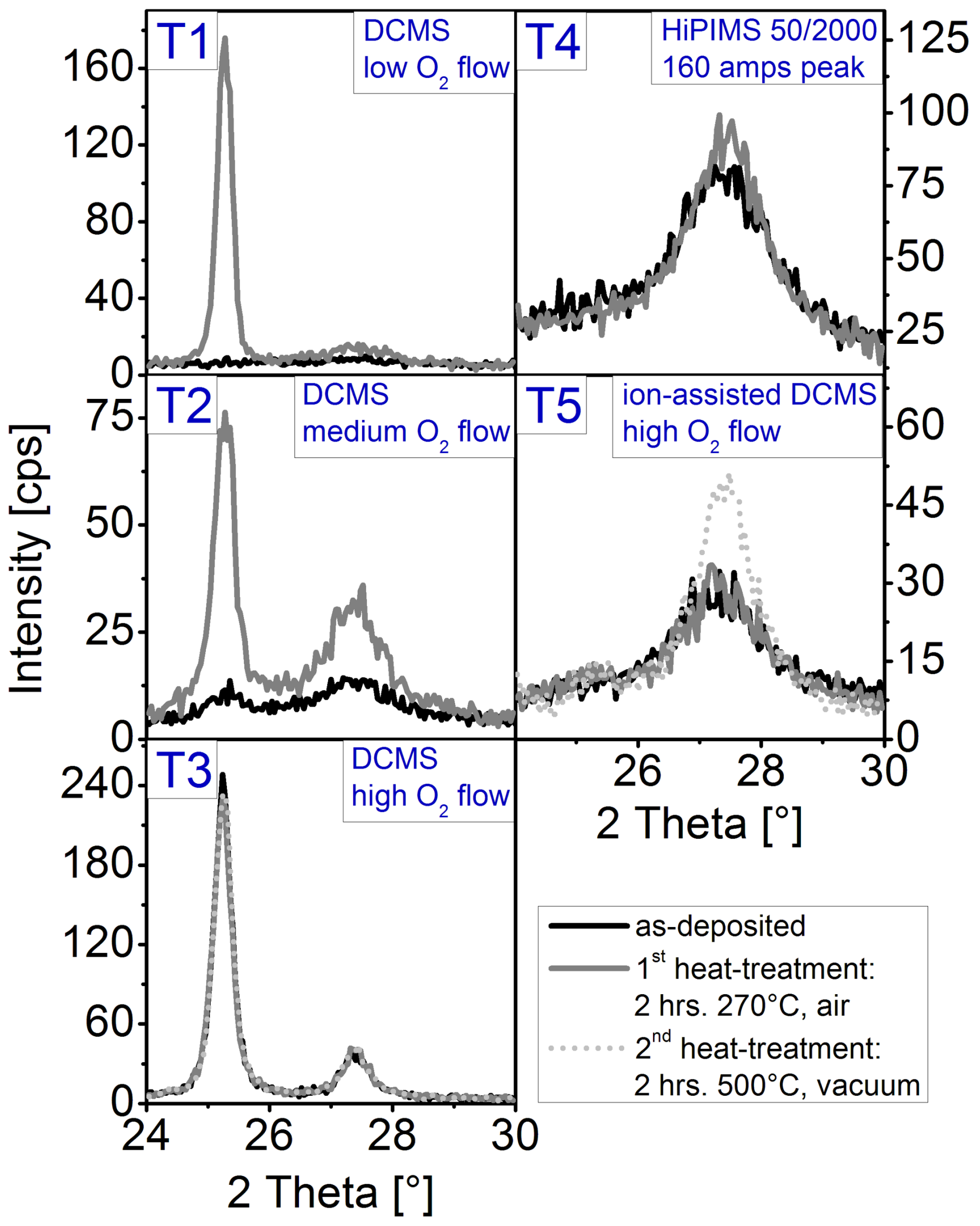

Figure 15 (Figure_15.tif) 